\title{
Role of the South China Sea in Southern China rainfall: meridional moisture flux transport
}

\author{
Xiangting $\mathrm{Li}^{1,2}$. Chunzai Wang ${ }^{3,4,5}$. Jian Lan ${ }^{1,2}$
}

Received: 29 May 2020 / Accepted: 22 December 2020 / Published online: 17 January 2021

(c) The Author(s) 2021

\begin{abstract}
The South China Sea (SCS) serves as the main source of moisture for rainfall in Southern China (SC) and the meridional moisture transport to SC is dominated by wind changes during the first rainy season (April-June). El Niño-Southern Oscillation (ENSO) and Tropical Northwestern Pacific (TNWP) variability modulate the SC rainfall through anomalous anticyclonic circulation over the western North Pacific by strengthening the SCS meridional moisture transport to SC. However, our study indicates that the SCS is not only the intermediary in which ENSO or the TNWP affects the SC rainfall but also plays an independent role in the modulation of the SC rainfall. Notably, the SCS meridional moisture transport has a lower impact on the SC rainfall during the second rainy season (July-September), especially in July. At that time, the main cause of the SC rainfall is the southward moisture flux anomaly across its northern boundary with the anomalous cyclone over SC. This cyclone suppresses the moisture flux out of SC and leads to moisture convergence in SC. Moreover, we present a new concept by analyzing internal differences of moisture circulation during the second rainy season. Either strengthening the meridional moisture flux into SC across its southern boundary or suppressing the moisture flux out of SC across its northern boundary is important depending on whether or not the moisture from the SCS can converge in SC, which is mainly determined by the amplitude of moisture transport fluxes in SC.
\end{abstract}

Keywords South China Sea $\cdot$ Meridional moisture flux $\cdot$ Southern china rainfall $\cdot$ Rainy season

Supplementary Information The online version contains supplementary material available at https://doi.org/10.1007/s0038 2-020-05603-w.

Chunzai Wang

cwang@scsio.ac.cn

1 College of Oceanic and Atmospheric Sciences, Ocean University of China, Qingdao, China

2 Physical Oceanography Laboratory/Institute for Advanced Ocean Study, Ocean University of China, Qingdao, China

3 State Key Laboratory of Tropical Oceanography, South China Sea Institute of Oceanology, Chinese Academy of Sciences, Guangzhou 510301, China

4 Southern Marine Science and Engineering Guangdong Laboratory (Guangzhou), Guangzhou 511458, China

5 Innovation Academy of South China Sea Ecology and Environmental Engineering, Chinese Academy of Sciences, Guangzhou, China

\section{Introduction}

Located in the East Asia monsoon region and south of the Yangtze River, Southern China (SC) is a tropical-subtropical region with lengthy rainy seasons. Considering that the $\mathrm{SC}$ region is an important economic center and a densely populated region, it is necessary to explore the changes and associated factors of the SC rainfall. The rainy season in SC, which lasts from April to September (Ding 1992; Gao et al. 2017), can be traditionally divided into two periods: the first rainy season (April to June; AMJ) and the second rainy season (July to September; JAS) by the different rainfall properties (Ma et al. 2018; Ding and Wang 2008; Gu et al. 2018; Fang et al. 2012). The first rainy season is mainly dominated by frontal rainfall and has a strong relationship with large-scale moisture flux transport. That is to say, the $\mathrm{SC}$ rainfall in the first rainy season is strongly affected by monsoon circulation, while the second rainy season usually has a strong relationship with tropical weather systems, such as tropical cyclones (Lin et al. 2006; Wu et al. 2011). 
Many studies have pointed out that the migration of the Western Pacific Subtropical High (WPSH) leads to the development of the East Asian monsoon, and further leads to the moving of the rainbelt in East Asia (Ding 1992; Ding and Wang 2008). Usually, the rainfbelt of East Asia is located $5^{\circ}-8^{\circ}$ latitude north of the WPSH ridge line. From April to mid-June, the WPSH ridge line usually lies south of $20^{\circ} \mathrm{N}$, and the major rainbelt occurs over South China, corresponding to the first rainy season. After mid-June, the WPSH moves northward rapidly to $20^{\circ} \mathrm{N}-25^{\circ} \mathrm{N}$. The East Asian monsoon and the major rainbelt move to middle and lower reaches of the Yangtze River and cause the noted Meiyu rainy season (Tanaka 1992; Zeng et al. 2019). At mid-July, the WPSH continues to move to $25^{\circ} \mathrm{N}-30^{\circ} \mathrm{N}$. The summer monsoon continues to strengthen, and the major rainbelt moves to the Yellow River Valley. Finally at the beginning of August, the WPSH ridge line reaches its northernmost position, the monsoon and rainbelt reach North and Northeast China (Matsumoto 1997). Particularly, many tropical weather systems such as tropical cyclones move along the southwest side of the WPSH and come to SC, bringing a great amount of moisture for the second rainy season of SC.

Moisture flux transport and its convergence/divergence play important roles in the process of precipitation ( $\mathrm{Li} 1999$; Sun et al. 2019). There are several channels of moisture flux that can influence rainfall in the East Asian monsoon region (Zhou and Yu 2005). El Niño-Southern Oscillation (ENSO), the Indian Ocean and the western Pacific Ocean and other factors, such as westerlies, can all modulate the rainfall in the East Asian monsoon region including SC (Wang et al. 2019; Leung et al. 2020; Xie and Wang 2020). However, most of the moisture transport channels from tropical zones that affect rainfall in the East Asian monsoon region are moving across the South China Sea (SCS). The SCS moisture flux is closely related to rainfall in East Asia, especially in SC. Huang et al. (1998) showed that the meridional moisture flux is stronger than the zonal moisture flux in East Asia. The summer monsoon precipitation in East Asia is mainly caused by the moisture advection brought by the East Asian summer monsoon over the SCS; while the advection caused by the Indian monsoon is dry advection, which can influence the convergence and divergence moisture transport. Li (1999) believed that the SCS is the most significant supplier of the East China summer rainfall based on analyses of the moisture flux and water balance in the SCS during late spring and summer. Some other studies have suggested that the SCS is simply an important channel of moisture transportation, but its own moisture does not change significantly (Chen et al. 2004). Thus, the roles of the SCS in the East Asian summer rainfall are still controversial and need to be further studied. Moreover, studies show that the effects of the SCS on the SC rainfall are different between the northern and southern areas (Wang et al. 2018). The northern part of the SCS can be a moisture sink when SC is dry and a moisture source when SC is wet. However, the southern part of the SCS always tends to be a moisture sink in summer (Chen et al. 1983).

As the wind variation plays an important role in moisture circulation (Herdies et al. 2002; Zhang and Sumi 2002; Wang et al. 2013), the behavior of the SCS moisture flux changes greatly together with the SCS monsoon during different seasons. The SCS monsoon is an important component of the East Asian monsoon system. However, the SCS monsoon is not always consistent with the East Asian monsoon. Especially, in the second rainy season, the main active region of the East Asian monsoon is much farther north than the SCS. For example, we find the moisture provided by the East Asian monsoon in August shows low correlation with the SCS moisture flux. Previous studies mainly focus on the variations of the whole monsoon, or the rainbelt in the corresponding time, such as the SC rainfall in the first rainy season and the rainfall of middle and lower reaches of the Yangtze River in Meiyu rainy season. As mentioned, the SCS meridional wind and moisture flux behave differently from the East Asian monsoon. However, little attention has been given to the differences between the influences of the SCS moisture flux on the SC rainfall in different seasons and the dynamical mechanisms behind it.

In this study, we aim to explore the different mechanisms behind the relationship of the SCS meridional moisture flux and SC rainfall, and study the characteristics (channel or source) of the SC rainfall played by the SCS. For the first rainy season, we investigate how the SCS meridional moisture flux influences the SC rainfall together with other factors, such as ENSO and the Tropical Northwest Pacific (TNWP). The SCS plays as an intermediary of other regions affecting the $\mathrm{SC}$ rainfall, but also is an independent moisture source of SC rainfall anomalies. For the second rainy season, we show the reason why the relationship between the SCS meridional moisture flux and SC rainfall is lower than that in the first rainy season, especially the relationship showing a significant decline in July. Moreover, we explore internal differences in moisture circulation between the three months of the second rainy season and explain different mechanisms that modulate the SC rainfall.

The remainder of the article is organized as follows: Sect. 2 introduces the data and methods employed in this study. In Sect. 3, we analyze the characteristics of the SC rainfall and SCS meridional moisture flux. Section 4 outlines the investigation of the relationship between the SC rainfall and SCS meridional moisture flux in the first rainy season. In Sect. 5, we investigate why the correlation is weak in the second rainy season, especially in July; we also explore internal differences in moisture circulation between the three months of the second rainy season and attempt to explain different mechanisms. Section 6 provides the conclusions and a summary. 


\section{Data and methods}

\subsection{Data and indices}

The precipitation data used in this study are from the basic meteorology historical dataset of stations released by the National Meteorological Information Centre (NMIC; http://data.cma.cn) of the China Meteorological Administration (CMA) and NOAA's Precipitation Reconstruction over Land (PREC/L; https://psl.noaa.gov/data/gridded/ data.precl.html) (Chen et al., 2002). The station precipitation data have been verified by NMIC. The horizontal resolution of PREC/L is $2.5^{\circ} \times 2.5^{\circ}$, and both precipitation datasets are from 1979-01 to 2018-12 Other data are the monthly means of daily mean data of the European Centre for Medium-Range Weather Forecasts (ECMWF) ERA Interim dataset (https://apps.ecmwf.int/datasets/data/ interim-full-moda/levtype $=\mathrm{sfc} /$ ) $($ Berrisford et al. 2009; Dee et al. 2011), including the vertical integral of moisture flux, the vertical integral of divergence of moisture flux, wind, specific humidity and geopotential height from 1000 to $200 \mathrm{hPa}$. The horizontal resolution of the ERA Interim dataset is $0.75^{\circ} \times 0.75^{\circ}$, and the period is from 1979-2001 to 2018-2012. The indices of the WPSH (area, intensity, ridge line, westernmost point) are provided by National Climate Center of the CMA (https://cmdp.ncccma.net/Monitoring/cn_stp_wpshp.php). For comparison, we also use the Global Precipitation Climatology Project (GPCP; https://psl.noaa.gov/data/gridded/data.gpcp.html) (Adler et al. 2018) monthly precipitation data to verify our results.

In this study, we define the SC rainfall index as the average station rainfall anomalies over the region from $108^{\circ} \mathrm{E}$ to $120^{\circ} \mathrm{E}$ and from $21^{\circ} \mathrm{N}$ to $29^{\circ} \mathrm{N}$. Considering that the northern part of the SCS has a closer relationship with the SC rainfall, we will use the northern part of the SCS instead of the whole SCS area in this work. The SCS meridional moisture flux index is defined as the average meridional moisture flux anomalies from $108^{\circ} \mathrm{E}$ to $120^{\circ} \mathrm{E}$ and from $15^{\circ} \mathrm{N}$ to $21^{\circ} \mathrm{N}$ (Fig. 1). The TNWP region is defined from $120^{\circ} \mathrm{E}$ to $138^{\circ} \mathrm{E}$ and from $3^{\circ} \mathrm{N}$ to $10^{\circ} \mathrm{N}$. Further, we define the annual indices by calculating the mean values of the SC rainfall index and SCS meridional moisture flux index in the first and second rainy seasons. Based on these annual indices, positive and negative cases are identified by the criterion that the annual indices exceed their one standard deviation in the time series (Table 1).

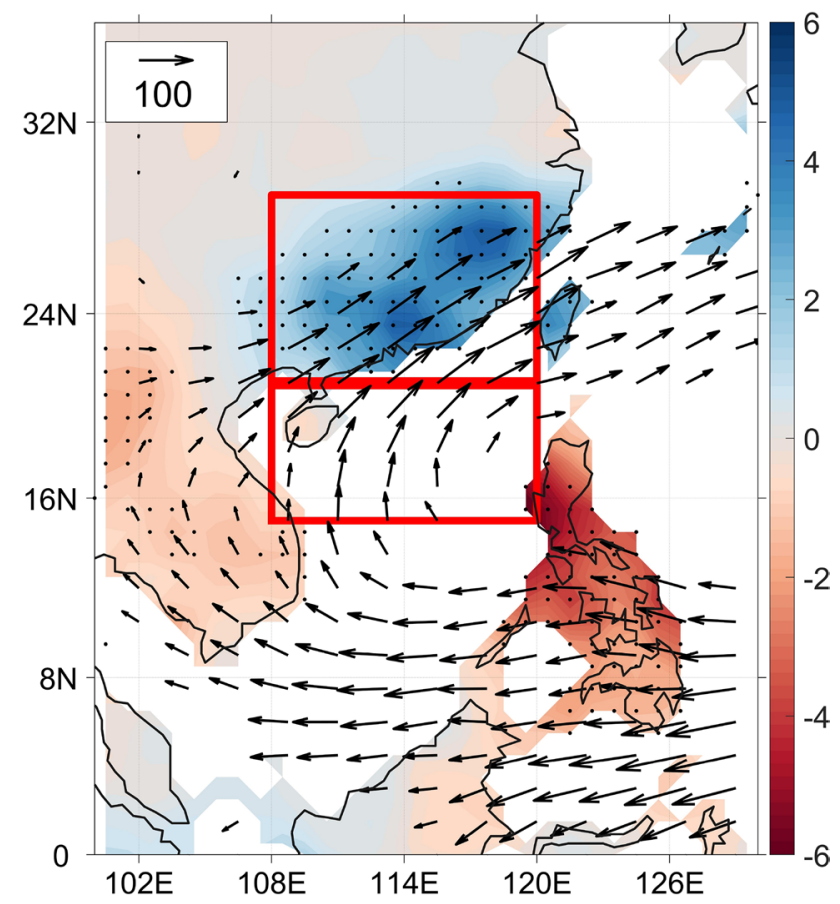

Fig. 1 Composite of land rainfall (shading; mm/day) and moisture flux (vectors; $\mathrm{kg} \mathrm{m}^{-1} \mathrm{~s}^{-1}$ ) anomalies of the positive $\mathrm{SC}$ rainfall cases minus those of the negative cases in the first rainy season (AMJ). Rainfall with $95 \%$ or more confidence is shaded with dots, and moisture fluxes less than $95 \%$ confidence are omitted. The red boxes refer to the $\mathrm{SC}$ region $\left(108^{\circ} \mathrm{E}-120^{\circ} \mathrm{E}, 21^{\circ} \mathrm{N}-29^{\circ} \mathrm{N}\right)$ and the northern part of the $\operatorname{SCS}\left(108^{\circ} \mathrm{E}-120^{\circ} \mathrm{E}, 15^{\circ} \mathrm{N}-21^{\circ} \mathrm{N}\right)$

\subsection{Moisture flux and decomposed moisture flux anomaly}

The vertical integral of moisture flux $(\vec{Q})$ can be calculated as follows:

$\vec{Q}=-\frac{1}{g} \int_{p_{s}}^{p_{t}} q \vec{V} d p$

where q, g, p and $\vec{V}$ represent the specific humidity, gravity, pressure and horizontal wind vector, respectively. Additionally, $p_{s}$ and $p_{t}$ are the pressures at the ground surface and top of the troposphere, usually set at $1000 \mathrm{hPa}$ and $200 \mathrm{hPa}$, respectively. The moisture content above $200 \mathrm{hPa}$ is considered to be negligible (Trenberth 1991; Li et al. 2013).

The moisture flux anomaly $(u q)^{\prime}$, can be decomposed into the following components (Wang et al. 2013):

$$
\begin{aligned}
(u q)^{\prime} & =u q-u_{M} q_{M} \\
& =\left(u_{M}+u^{\prime}\right)\left(q_{M}+q^{\prime}\right)-u_{M} q_{M} \\
& =u^{\prime} q_{M}+u_{M} q^{\prime}+u^{\prime} q^{\prime}
\end{aligned}
$$


Table 1 The positive and negative anomalous years of the SC rainfall and SCS meridional moisture flux index in the (a) first rainy season (AMJ) and (b) second rainy season (JAS), based on the criterion that the mean anomalies exceed one standard deviation

\begin{tabular}{lll}
\hline Years & SC rainfall & SCS meridional moisture flux
\end{tabular}

(a) First rainy season, AMJ

positive years

1993, 1998, 2005, 2006, 2010, 2016

1985, 1988, 1991, 2004, 2009, 2011, 2018

1994, 1997, 1999, 2002

1986, 1989, 1998, 2003, 2005, 2011
1983, 1993, 1998, 2005, 2012, 2016

1982, 1985, 1996, 2004, 2009, 2011, 2018

1997, 2013, 2017

1986, 1989, 1992, 2000, 2001, 2009, 2012 where subscript $\mathrm{M}$ represents the climatological monthly mean and the prime represents the variation from the climatological monthly mean: $u^{\prime}=u-u_{M}$ and $q^{\prime}=q-q_{M}$.

\subsection{Partial correlation}

In this study, we use partial correlation to isolate the impact of the SCS meridional moisture on the SC rainfall from other factors. The definition of the partial correlation follows (Saji and Yamagata 2003):

$r_{Y 1,2}=\frac{r_{Y 1}-r_{Y 2} r_{12}}{\sqrt{\left(1-r_{12}^{2}\right)\left(1-r_{Y 2}^{2}\right)}}$ where $r_{Y 1}$ is the simple correlation between $\mathrm{Y}$ and $X_{1}$. Similarly, $r_{Y 2}$ is the correlation between $\mathrm{Y}$ and $X_{2}$, and $r_{12}$ is the correlation between $X_{1}$ and $X_{2}$.

\section{Characteristics of SC rainfall and SCS meridional moisture transport}

The seasonal cycles of the SC rainfall and SCS meridional moisture flux are shown in Fig. 2a. The heaviest rainfall in SC (blue line) occurs from April to August, corresponding to the first and second rainy seasons (the rainfall in September is lower than the rainfall in these months but still strong enough to be included in the second rainy season). Moisture circulation in the adjacent East Asia monsoon region, especially moisture flux across the SCS, plays an
Fig. 2 a Seasonal cycle of the $\mathrm{SC}$ rainfall (blue line) and SCS meridional moisture flux (red line). The shaded areas indicate the one standard deviation ranges. b Correlation between the SC rainfall and SCS meridional moisture flux in each month during 1979-2018 (a) Annual cycle

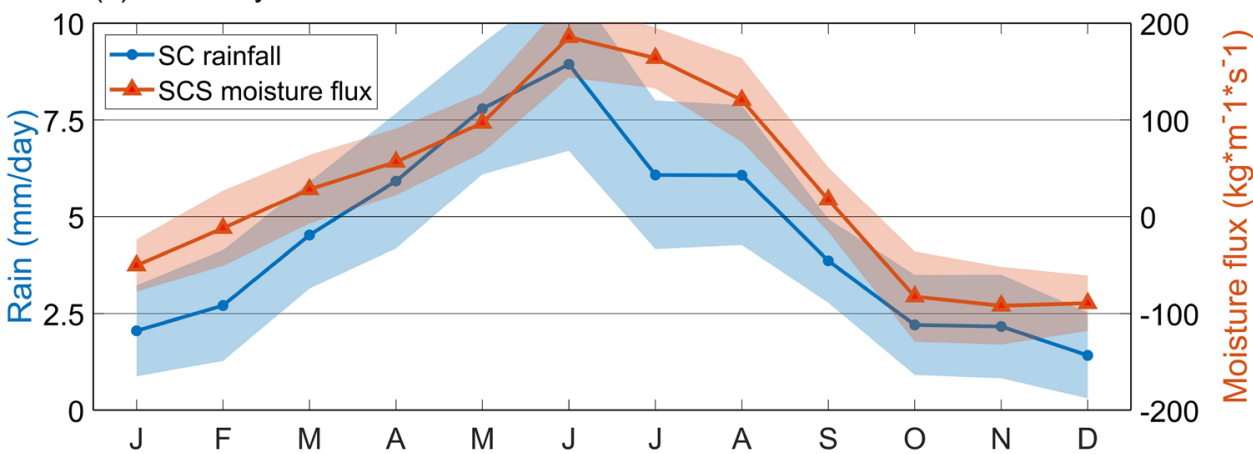

(b) Correlation between SC rainfall \& SCS moisture flux

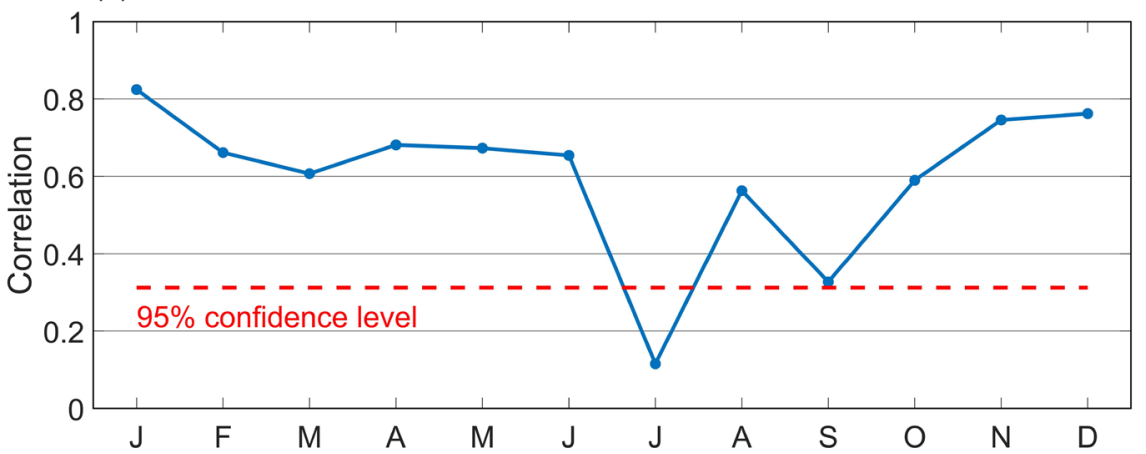


important role in the precipitation of SC. As shown in Fig. 2a, the SCS meridional moisture flux index (red line) shows a coincident season cycle with the SC rainfall (blue line). The index is negative from October to February and positive from March to September. Obviously, the SCS meridional moisture transport changes along with the monsoon over the SCS. The summer monsoon can bring plenty of moisture from the SCS to SC, while the dry winter monsoon will reduce the $\mathrm{SC}$ rainfall. Figure $2 \mathrm{~b}$ shows the correlation between the SC rainfall index and the SCS meridional moisture flux index in each month. The correlation between the SC rainfall and SCS meridional moisture flux in the first rainy season (AMJ) is better than that in the second rainy season (JAS). Moreover, the correlation in July could be as low as 0.12 , which cannot pass the significance test (Fig. 2b).

Figure 3 shows the time series of the SC rainfall and SCS meridional moisture flux in the first and second rainy seasons from 1979 to 2018. The correlation between these two indices in the first rainy season can reach 0.66 , while it can reach only 0.34 in the second rainy season. Obviously, the relationship between the SC rainfall and SCS meridional moisture flux in the first rainy season is better than that in the second rainy season. In addition, we can see that the rainfall displays significant differences between the first and second rainy seasons (Yuan et al. 2019), which implies that different mechanisms are controlling the SC rainfall in these two rainy seasons.
As shown in Eq. (1), the moisture flux consists of specific humidity and wind. We further investigated these two components. Figure 4a shows the seasonal cycle of SCS specific humidity (blue line) and the SCS meridional wind component (red line). We can see that the meridional wind component shows a cycle that is more similar to moisture flux than specific humidity. The effects of humidity and wind changes on moisture transport can be separated by the decomposition as shown in Eq. (2). Figure 4b shows the seasonal cycle of the vertically integrated composite SCS meridional moisture transport and three decomposed components of the anomalous SC rainfall years $\left(\mathrm{SC}\right.$ rainfall ${ }^{+}-\mathrm{SC}_{\text {rainfall }}{ }^{-}$). The SCS meridional moisture flux anomalies are mainly determined by wind changes, except in July, in which the contributions of specific humidity and wind are similar. The nonlinear term of $u^{\prime} q^{\prime}$ is small enough to be ignored. Overall, the wind change is the dominant factor in SCS meridional moisture flux changes.

Further, as the component of the East Asian Monsoon, the variations of the SCS meridional wind are strongly driven by the WPSH. Figure 5a shows the scatterplots of the SCS meridional wind versus the WPSH ridge. We can see that the SCS meridional wind increases with the northward migration of the WPSH from April to June when the WPSH ridge is on the east of the SCS, and then decreases with the continued northward migration of the WPSH from June to August when the WPSH ridge is on the northeast of the SCS. Particularly in September, the WPSH retreated southward and
Fig. 3 The time series of the SC rainfall and SCS meridional moisture flux and their relationships in a the first rainy season (AMJ) and $\mathbf{b}$ the second rainy season (JAS) in SC. Q_v means meridional moisture flux
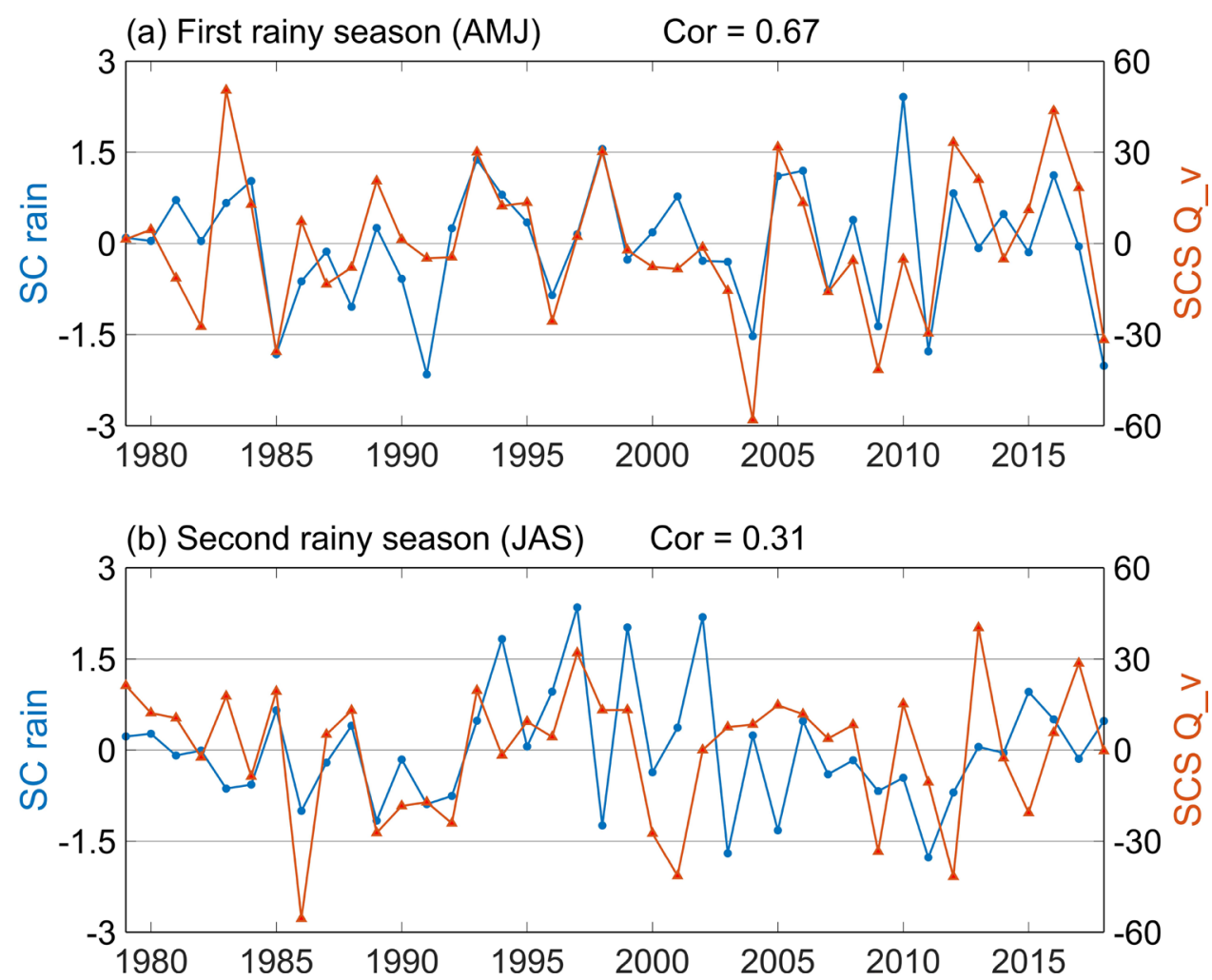
Fig. 4 a Seasonal cycle of the SCS specific humidity (blue line) and SCS meridional wind component (red line). V means the SCS meridional wind. The shaded areas indicate their one standard deviation ranges. b The vertically integrated composite of the SCS meridional moisture transport variations (blue line) and the associated decomposed components (red, purple and green lines) of the positive SC rainfall cases minus that of negative cases that exceed one standard deviation (unit: $\mathrm{kg} \mathrm{m}^{-1} \mathrm{~s}^{-1}$ )
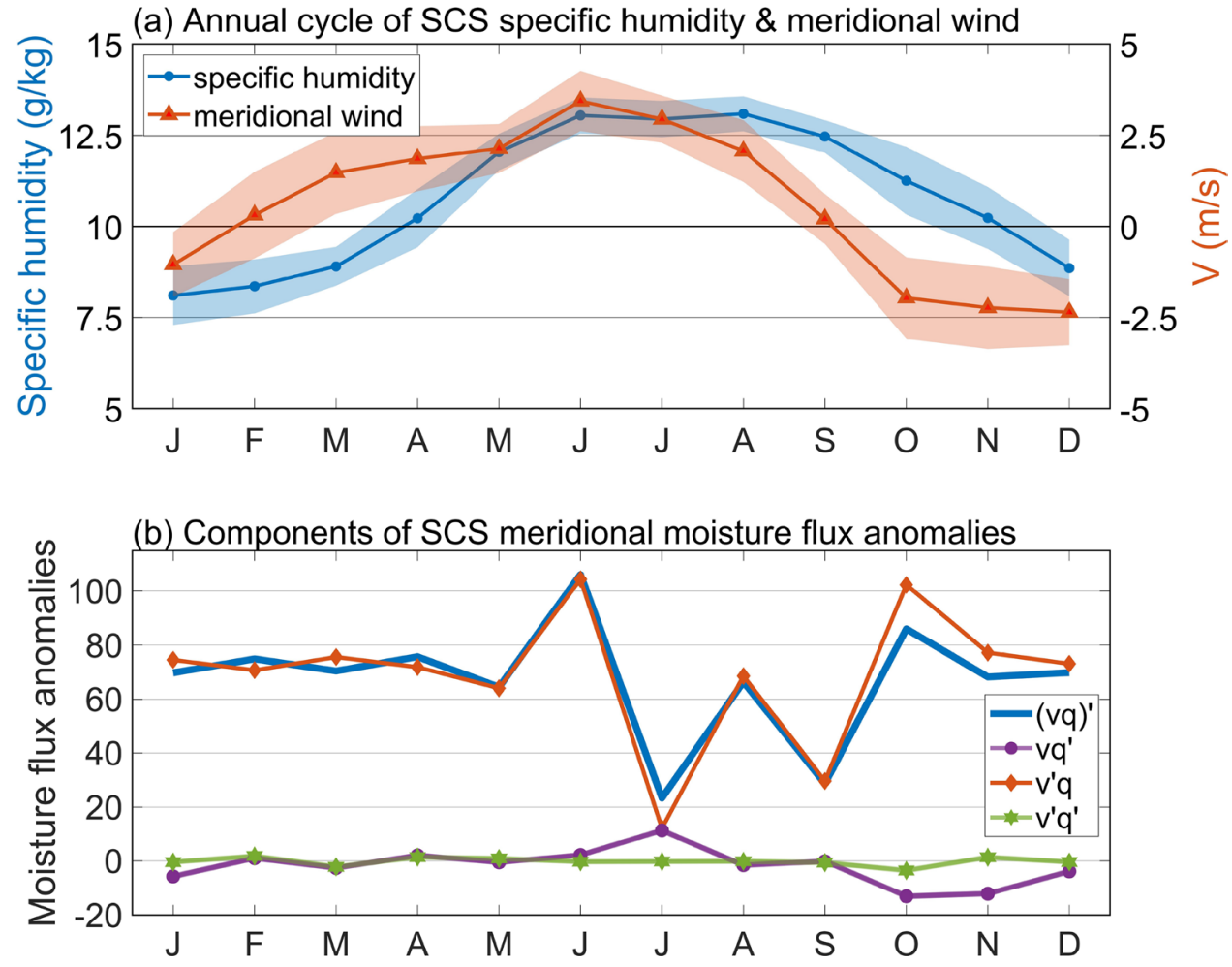

Fig. 5 Scatterplots of a the SC meridional wind and $\mathbf{b}$ the SC rainfall index versus the WPSH ridge. Each point corresponds to a month of the year. Different months are shown in different colors
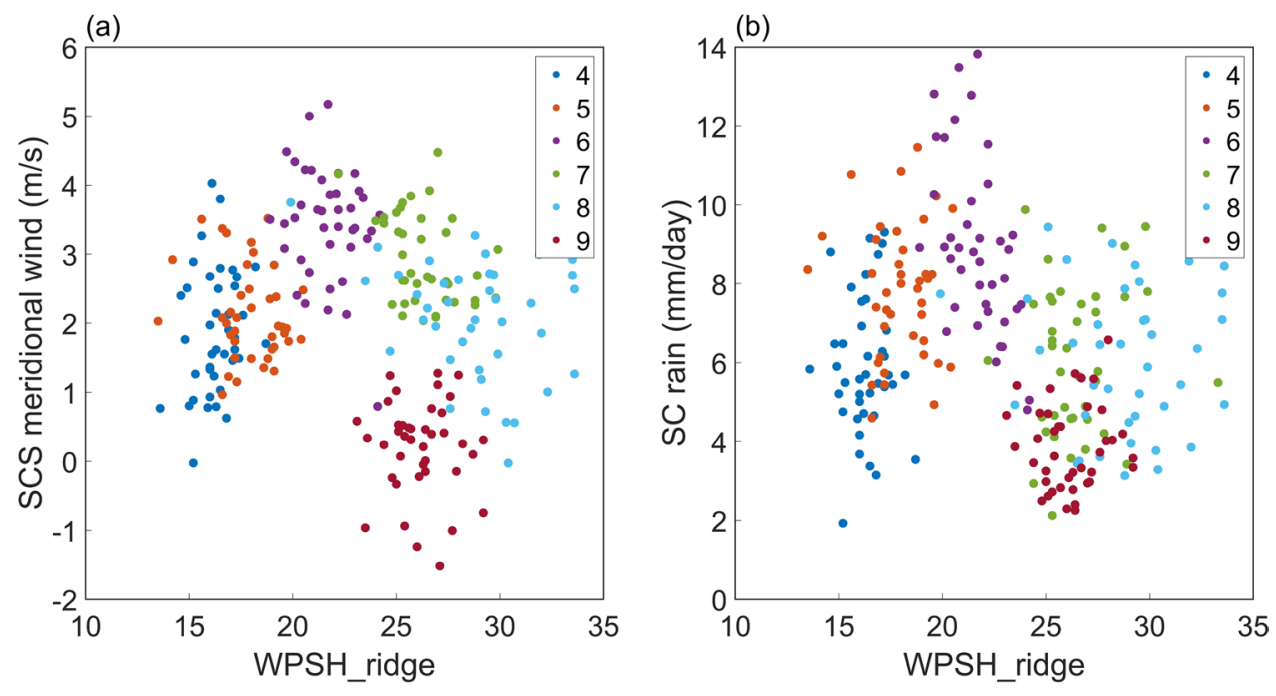

the SCS is in the monsoon transition period, and thus the meridional wind is near to 0 . As a result, although the SCS meridional wind is strongly driven by the shift of the WPSH ridge, the relationship between them is different according to whether the WPSH ridge is farther north than the SCS. The correlation between the WPSH ridge and SCS is low for the whole time series.

Figure $5 \mathrm{~b}$ shows the scatterplots of the SC rainfall versus the WPSH ridge. It seems that the SC rainfall has a good relationship with the WPSH as well as the SCS meridional wind from April to June. But the things have changed and their relationship becomes complex during the second rainy season. We will explore this further in later sections. 


\section{Roles of SCS meridional moisture flux in the first SC rainy season}

\subsection{Composites of SC rainfall and SCS moisture flux anomalies}

From Table 1a, most of the years of the anomalous SC rainfall and SCS meridional moisture flux cases are coincident in the first rainy season. Actually, the SC rainfall and SCS meridional moisture flux still exhibit similar anomalies across the other years which do not seem to coincide in Table 1a. Taking 2012 as an example, Table 1a indicates that 2012 is the year with above normal SCS meridional moisture flux but not the SC rainfall in the first rainy season. However, Fig. 3a shows that the SC rainfall in 2012 is also a local maximum, though not above the one standard deviation threshold. This also proves the close relationship

\section{(a) Anomalous SC rain cases, AMJ}

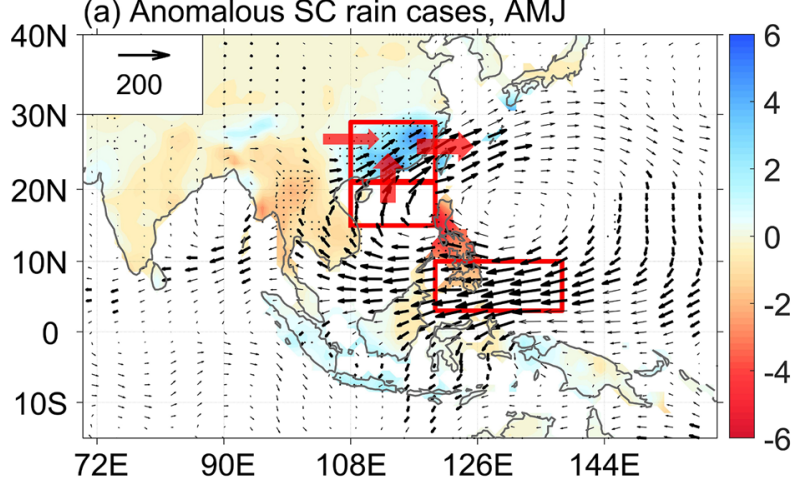

(b) Anomalous SCS moisture flux cases, AMJ

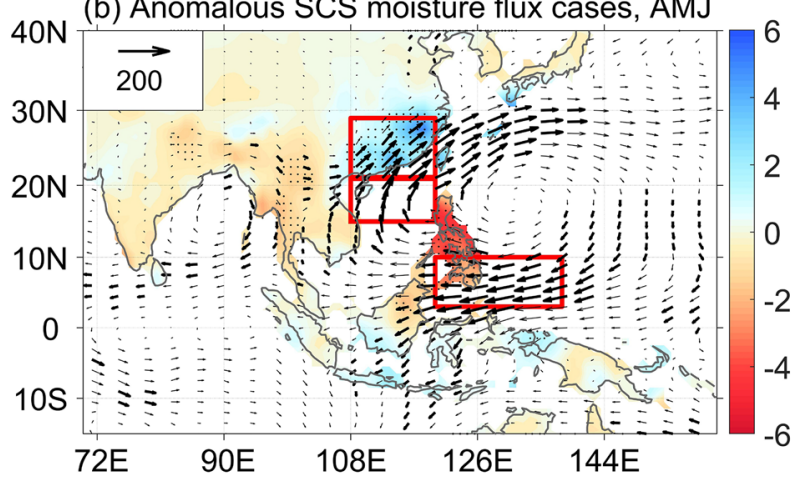

Fig. 6 Composite rainfall (shading; $\mathrm{mm} /$ day) and moisture flux (vectors; $\mathrm{kg} \mathrm{m}^{-1} \mathrm{~s}^{-1}$ ) anomalies of a positive $\mathrm{SC}$ rainfall cases minus those of the negative SC rainfall cases and $\mathbf{b}$ positive SCS meridional moisture flux cases minus those of the negative SCS meridional moisture flux cases (beyond one standard deviation) in AMJ. The three red boxes from north to south refer sequentially to SC, the SCS and the Tropical Northwest Pacific (TNWP; $120^{\circ} \mathrm{E}-138^{\circ} \mathrm{E}$, $3^{\circ} \mathrm{N}-10^{\circ} \mathrm{N}$ ). The red arrows in a show the schematic anomalous moisture transport across each boundary. Rainfall with $95 \%$ or more confidence is shaded with dots, and moisture fluxes greater than $95 \%$ confidence are in bold between the anomalous SC rainfall and SCS meridional moisture flux.

With the anomalous cases of SCS meridional moisture flux in Table 1, Fig. 6 shows the composite moisture flux and rainfall anomalies over East Asia for the anomalous SC rainfall years (SC rainfall ${ }^{+}-\mathrm{SC}$ rainfall $^{-}$; Fig. 6a) and for the anomalous SCS meridional moisture flux years (SCS meridional moisture flux ${ }^{+}-\mathrm{SCS}$ meridional moisture flux ${ }^{-}$; Fig. 6b) in AMJ. When there is above normal rainfall in $\mathrm{SC}$, an anomalous anticyclonic distribution of moisture flux appears over the Philippine Sea. Located west of the anticyclonic region, strong anomalous meridional moisture flux transport is northward from the SCS to SC. The abundance of water coming from the strengthened SCS meridional moisture transport supports the heavy rainfall over SC. Moreover, this moisture circulation and rainfall distribution of the anomalous SC rainfall cases coincide exactly with the results in the anomalous SCS meridional moisture flux cases, which indicates the close relationship between the SC rainfall and SCS meridional moisture flux. As a supplementary, the composites of positive only or negative only cases for the SCS meridional moisture flux or SC rainfall are shown in Fig. S1.

\subsection{Influences of remote factors}

a. TNWP westward moisture flux and adjacent moisture flux over East Asia

From the anomalous anticyclonic circulation shown in Fig. 6, it seems that the extra moisture transported to SC, which contributes to the positive SC rainfall, comes from the TNWP in AMJ. The correlation coefficient between the SCS meridional and TNWP westward moisture flux indices in AMJ is 0.51 . That means one quarter of the variance of meridional moisture flux over the SCS explained by that from the TNWP (square of the correlation coefficient).

To further explore the effect of the TNWP on the SC rainfall and its relationship with the SCS, we conduct a partial correlation analysis. Figure 7a shows the Pearson correlation, which is the so-called simple correlation between the SCS meridional moisture and moisture flux convergence over East Asia. The SCS meridional moisture flux is closely associated with an anomalous anticyclonic pattern over the WNP-SCS. This anomalous anticyclone strengthens the northward moisture flux from the SCS, bringing abundant water to SC. This action is vital for the precipitation process, leading to a Pacific-Japan (P-J) pattern (Tao et al. 2017; Yuan et al. 2019) with an anomalous moisture flux convergence over SC and a moisture flux divergence over the western Pacific, which means more rainfall over SC and less rainfall over the western Pacific. Figure $7 \mathrm{~b}$ shows a similar pattern as that in Fig. 7a; the TNWP westward 


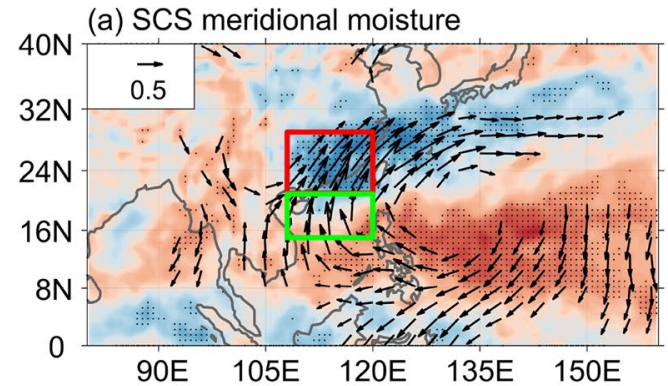

(c) SCS meridional moisture (TNWP removed)

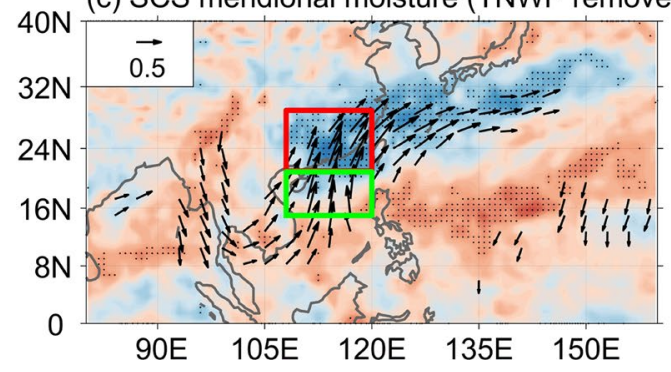

Fig. 7 Pearson correlations of moisture flux (vectors) and moisture flux convergence (shading) with a SCS index, and b TNWP index in AMJ. c Partial correlations of moisture flux and moisture flux convergence with SCS index in AMJ, with the signal of the TNWP index removed. d Partial correlations of moisture flux and moisture

moisture flux is also associated with the anomalous anticyclone. However, the TNWP westward moisture flux and SCS meridional moisture flux indices show something different in the partial correlation analysis (Fig. 7c, d). When the TNWP westward moisture flux signal is removed, there is still a distinct northward moisture flux towards SC in the partial correlation between the moisture flux over East Asia and the SCS meridional moisture flux (Fig. 7c). In addition, the distribution of the correlation result with moisture flux convergence is similar to that in Fig. 7a, implying that the relationship between the SC rainfall and SCS meridional moisture flux is robust and independent from the TNWP region. Figure $7 \mathrm{~d}$ shows the partial correlation with the signal of the SCS meridional flux removed. Under such conditions, the moisture from the TNWP area can be transported just westward to the Indian Ocean. Only a small moisture flux is transported into SC from the western boundary, which cannot lead to a significant moisture flux convergence over the SC region. This indicates that the influence of the TNWP westward moisture flux on the $\mathrm{SC}$ rainfall is mainly through the SCS, whereas the SC moisture does not directly come from the TNWP. It is worth mentioning that the index is not so sensitive to different definitions. We make some changes to the range of the TNWP index and the result shows little difference with the index defined in this paper (Fig. S2).

b. ENSO and adjacent moisture flux over East Asia (b) TNWP westward moisture

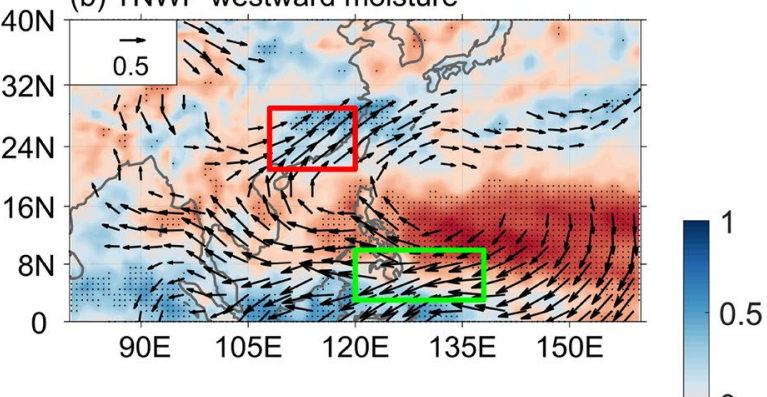

(d) TNWP westward moisture (SCS removed)

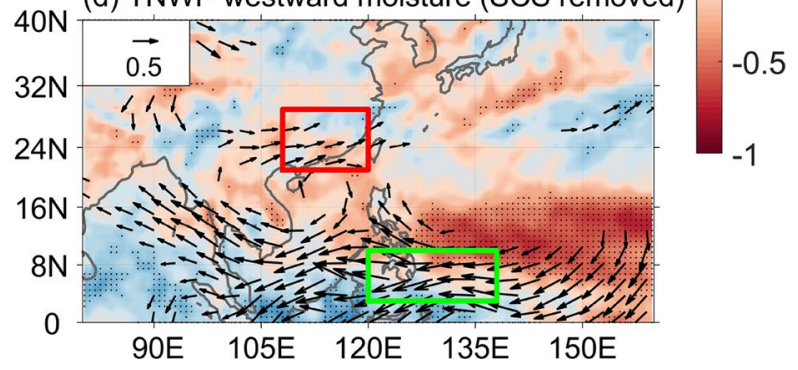

flux convergence with the TNWP index in AMJ, with the signal of the SCS index removed. Moisture flux convergence with $95 \%$ or more confidence is shaded with dots, and moisture flux less than $95 \%$ confidence is omitted

As mentioned above, we notice that the anomalous anticyclone over the WNP-SCS plays an important role in modulating the relationship between the SCS meridional moisture flux and SC rainfall in the first SC rainy season. Considering that anomalous anticyclone is generally regarded as a response to El Niño events (Wang et al. 1999, 2000, 2009; Watanabe and Jin 2002; Xiao et al. 2020), it is worth examining the relationship among ENSO, the SCS and SC rainfall. Previous studies (Feng et al. 2011; Yuan and Yang 2012; Wang et al. 2018) have pointed out that eastern Pacific (EP)-El Niño has a positive correlation with the SC rainfall, while central Pacific (CP)-El Niño has a negative correlation with the SC rainfall. Moreover, some studies (Wang and Wang 2013; Jiang et al. 2019) further divide CP-El Niño into two types, as these types have different influences on the SC rainfall. Overall, EP-El Niño shows a positive correlation with the SC rainfall, and CP-El Niño does not have a clear or direct relationship with the SC rainfall. Therefore, we use the Nino 3 index $\left(150^{\circ}-90^{\circ} \mathrm{W}, 5^{\circ} \mathrm{N}\right.$ to $\left.5^{\circ} \mathrm{S}\right)$ in the previous winter (December, January and February) to refer to the strength of ENSO in this work.

Figure 8a shows the Pearson correlations of the SC rainfall with adjacent moisture flux and moisture flux convergence in AMJ. There is strong northward moisture transport from the SCS to SC with an anomalous anticyclone over the WNP-SCS, which is similar to that shown in Fig. 7a. As shown in Fig. 6, the anomalous SC rainfall and SCS 

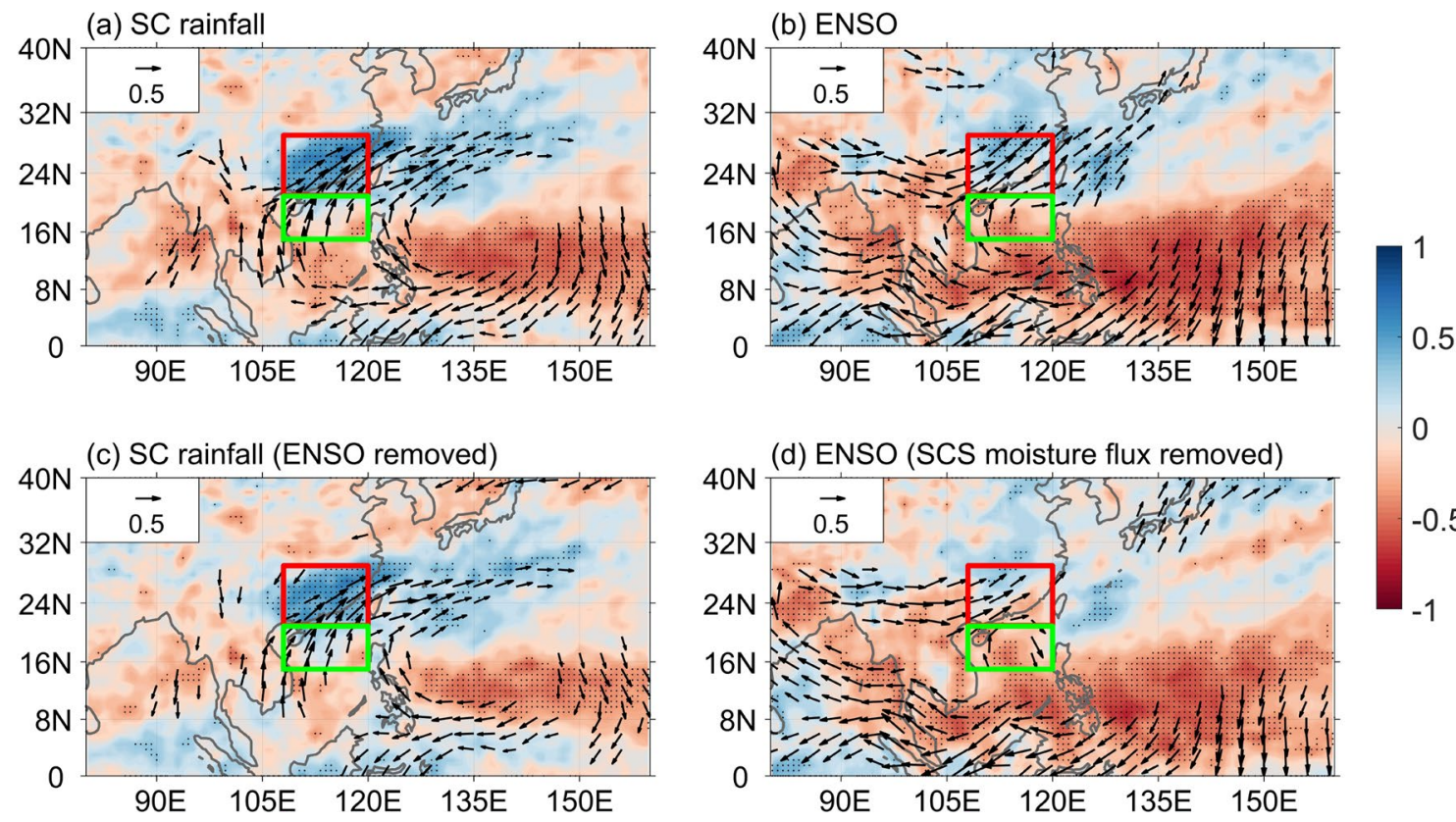

(d) ENSO (SCS moisture flux removed)

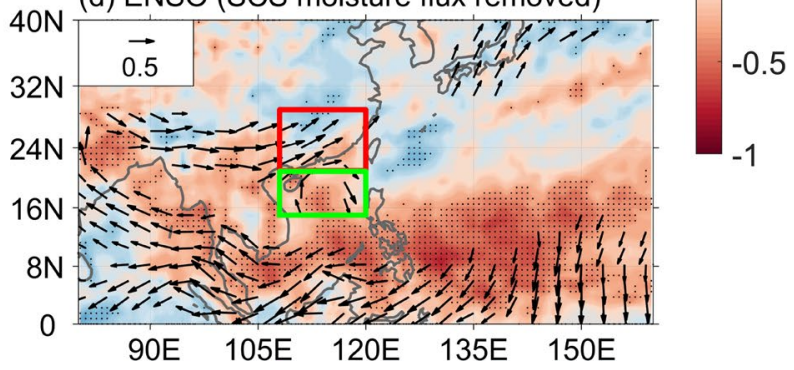

Fig. 8 Pearson correlations of moisture flux (vectors) and moisture flux convergence (shading) with a SC rainfall index, and b Nino 3 index in AMJ. c Partial correlations of moisture flux and moisture flux convergence with SC rainfall index in AMJ, with the signal of the Nino3 index removed. d Partial correlations of moisture flux and

meridional moisture flux are associated with similar atmospheric circulations in the first rainy season. Figure $8 \mathrm{~b}$ shows the Pearson correlation of the Nino 3 index with the moisture flux and moisture flux convergence over East Asia. The strengthened SCS meridional moisture flux appears in this correlation, and the moisture convergence in SC favors the rainfall there. It is reasonable to say that there is a teleconnection between EP-El Niño and the SC rainfall by modulating SCS meridional moisture flux transported to SC. However, their relationship is not really significant, while the Nino 3 index seems to have a stronger relationship with the rainfall over the middle and lower reaches of the Yangtze River. The correlation coefficient between the SCS meridional moisture flux and Nino 3 indices is 0.36 and only $13 \%$ of the variance of meridional moisture flux over the SCS in AMJ can be explained by Nino3 index in previous winter.

To remove the influence of ENSO, we perform a partial correlation analysis of the anomalous SC rainfall and adjacent moisture flux and moisture flux convergence, with the Nino 3 index removed (Fig. 8c). The pattern of partial correlation is similar to the Pearson correlation shown in Fig. 8a, except that the signal of the TNWP becomes weaker. The northward moisture flux still appears in the SCS, which indicates that the relationship between the SC rainfall and SCS meridional moisture is robust. That is, the SCS is not only a direct source of the SC rainfall but also an intermediary in the teleconnection of ENSO and the SC rainfall. When

moisture flux convergence with Nino 3 index in AMJ, with the signal of the SCS meridional moisture flux removed. Moisture flux convergence with $95 \%$ or more confidence is shaded with dots, and moisture flux less than $95 \%$ confidence is omitted

the signal of the SCS meridional moisture flux is removed (Fig. 8d), the anomalous SC rainfall cannot pass the confidence test even though some moisture flux is transported into SC by its western boundary with anomalous anticyclonic circulation over the Bay of Bengal and Indo-China Peninsula.

From Sects. $4.2 \mathrm{a}$ and $\mathrm{b}$, we can conclude that the SCS is not only a direct source of SC rainfall change but also an intermediary in the teleconnection among ENSO, the TNWP and the SC rainfall. ENSO and the TNWP can modulate the SC rainfall by influencing the SCS meridional moisture flux.

\subsection{Moisture flux across the boundaries of SC in AMJ}

As mentioned above, rainfall is usually dominated by the convergence and divergence of moisture flux. Figure 9 shows the composite of the moisture flux anomalies across the SC boundaries for the positive and negative $\mathrm{SC}$ rainfall cases in AMJ and JAS. In AMJ, the moisture flux across the southern boundary contributes the most to the SC rainfall at nearly $60 \%$, which implies the important role of the SCS meridional moisture flux in the anomalous $\mathrm{SC}$ rainfall. In addition, moisture flux across the western boundary is second, while moisture flux across the eastern boundary has the opposite contribution (Fig. 9a). This result is consistent with the pattern shown in Figs. 1 and 8a. 
Fig. 9 Composites of the moisture transport anomalies (Sv) across each boundary of SC as well as the total moisture transport anomalies converged over the SC area for the positive and negative phases of SC rainfall (beyond one standard deviation) during the $\mathbf{a} \mathrm{AMJ}$ and $\mathbf{b}$ JAS. The percentages above the bars indicate the contributions of each boundary to the whole moisture flux anomalies transported into (positive cases) or out of (negative cases) SC
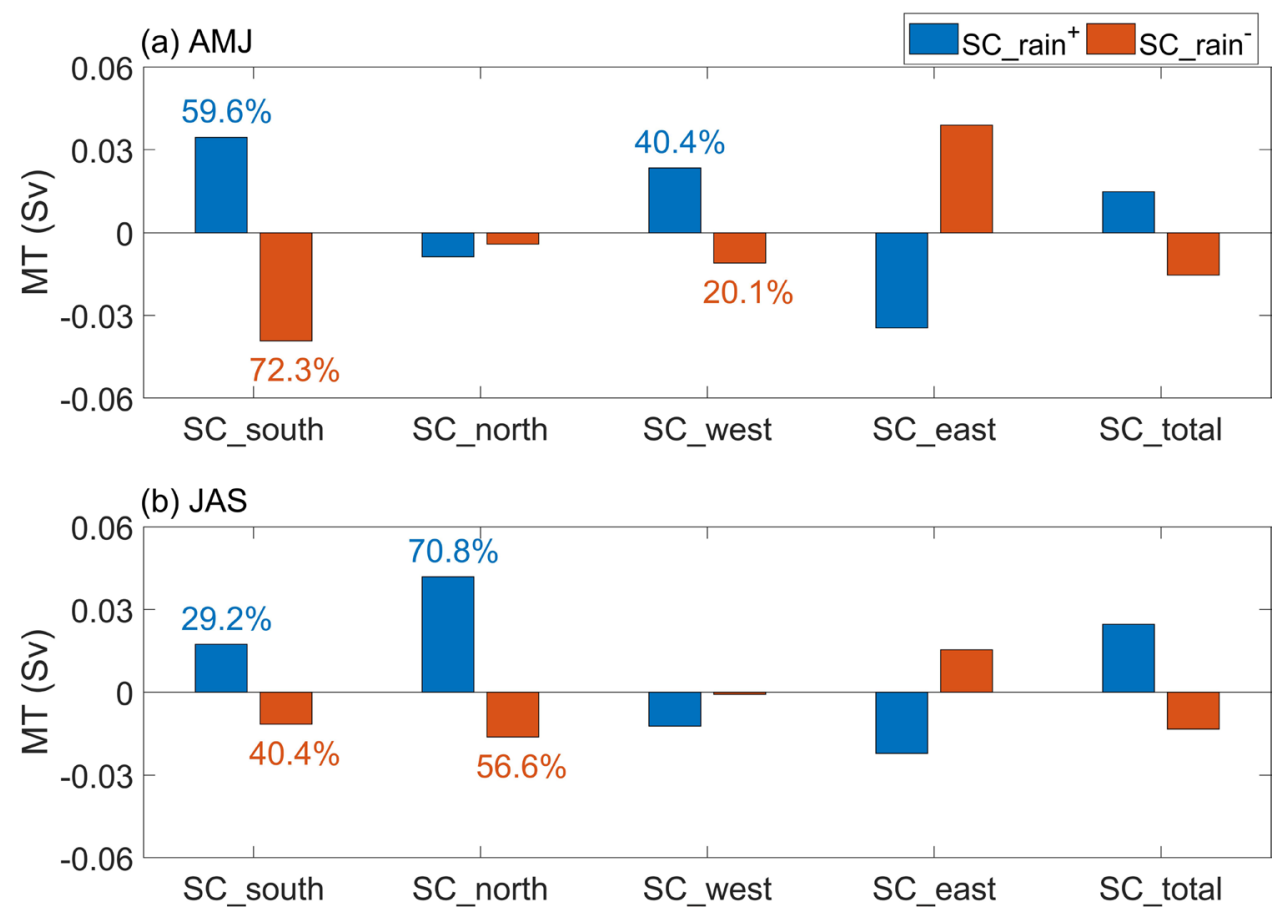

Located northwest of the anomalous anticyclone over the WNP-SCS, the strengthened meridional moisture flux from the SCS provides the dominant moisture for the anomalous SC rainfall, and the eastward moisture flux across the western boundary also has an effect. Part of the anomalous moisture was transported out of the $\mathrm{SC}$ region again through the eastern boundary. This process is already shown schematically in Fig. 6a. As components of the anomalous anticyclone, moisture flux anomalies across the southern and eastern boundaries have a strong relationship. We notice that the amplitude of moisture flux anomalies across the southern and eastern boundaries in negative $\mathrm{SC}$ rainfall years is higher than that in positive SC rainfall years. However, because of the strong relationship between these two boundaries, both moisture flux anomalies transported into and out of SC are synchronously stronger in negative SC rainfall years. Thus, the total moisture flux divergence over SC in the negative SC rainfall years is symmetric with that in positive years, meaning the magnitude of the $\mathrm{SC}$ rainfall anomalies is symmetric.

\section{Roles of SCS meridional moisture flux in the second rainy season}

\subsection{Why is the correlation weak in the second rainy season?}

In the previous sections, we mainly discuss the characteristics of the anomalous SC rainfall and SCS meridional moisture flux and study the positive relationship between (a) Anomalous SC rain cases, JAS

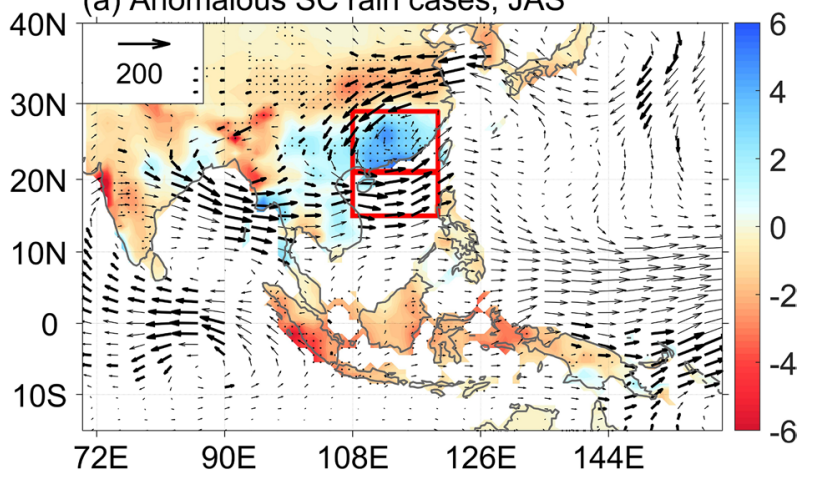

(b) Anomalous SCS moisture flux cases, JAS

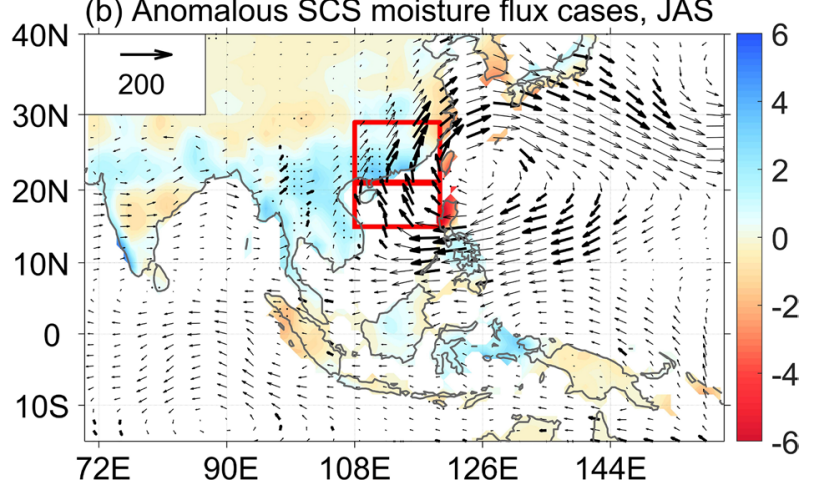

Fig. 10 Composite rainfall (shading; $\mathrm{mm} /$ day) and moisture flux (vectors; $\mathrm{kg} \mathrm{m}^{-1} \mathrm{~s}^{-1}$ ) anomalies of a positive $\mathrm{SC}$ rainfall cases minus those of the negative SC rainfall cases and $\mathbf{b}$ positive SCS meridional moisture flux cases minus those of the negative SCS meridional moisture flux cases (beyond one standard deviation) in JAS. Rainfall with $95 \%$ or more confidence is shaded with dots, and moisture fluxes greater than $95 \%$ confidence are in bold 
them in the first rainy season. However, as mentioned earlier, the correlation between the SC rainfall and SCS meridional moisture flux in the second rainy season is lower than that in the first rainy season. Similar to Fig. 6, we perform the same analyses for the relationship between the rainfall and moisture flux over East Asia in the second rainy season (JAS; Fig. 10).

Figure 10a shows a large anomalous cyclonic circulation over the SC region when the SC rainfall in JAS is positive, which leads to a convergence of moisture flux in the center of the anomalous cyclone, especially providing anomalous southward moisture flux across the northern boundary of SC. Moreover, the corresponding SCS moisture flux anomalies near the southern boundary are nearly eastward, with no moisture transported into SC. The composite moisture flux anomalies across the SC boundaries for positive and negative SC rainfall cases in JAS shown in Fig. 9b also support this finding. Most of the moisture flux transported into SC is from its northern boundary (near 71\%), and the moisture flux anomaly across the southern boundary contributes less than $30 \%$, while the zonal moisture flux (across the western and eastern boundaries) makes little contribution to the anomalous SC rainfall in the second rainy season. The anomalous anticyclone over the WNP-SCS in the composite SC rainfall result during AMJ disappears in the composite result during JAS. This implies that ENSO cannot regulate the relationship between the SC rainfall and SCS moisture flux; in fact, ENSO shows little impact on the SC rainfall during JAS (Fig. S3). In addition, there exists an asymmetry of moisture flux circulation in positive and negative SC rainfall years, as the moisture flux anomalies transported into SC across the northern and southern boundaries in positive cases are much stronger than those transported out of SC in negative $\mathrm{SC}$ rainfall cases, as shown in Fig. 9b. Thus, the amplitude of increased rainfall in positive cases is much larger than the amplitude of decreased rainfall in negative cases.

Additionally, Fig. 10b shows composite rainfall (shading) and moisture flux (vectors) anomalies for anomalous SCS meridional moisture flux years (SCS meridional moisture flux $^{+}-$SCS meridional moisture flux ${ }^{-}$), with anomalous anticyclonic circulation over the WNP-SCS. However, the anomalous anticyclone is farther north than that in AMJ (Fig. 6b), and SC is located west of the anomalous anticyclone in JAS instead of northwest in AMJ. As a result, the anomalous SCS meridional moisture flux transported into SC across the southern boundary and then out of SC across the northern boundary, with little moisture converging in SC and thus with little contribution to the SC rainfall. This finding also verifies that the relationship between the SC rainfall and SCS meridional moisture flux is not as good in the second rainy season.

A possible reason why the relationship between the moisture circulation and anomalous SC rainfall is so different in
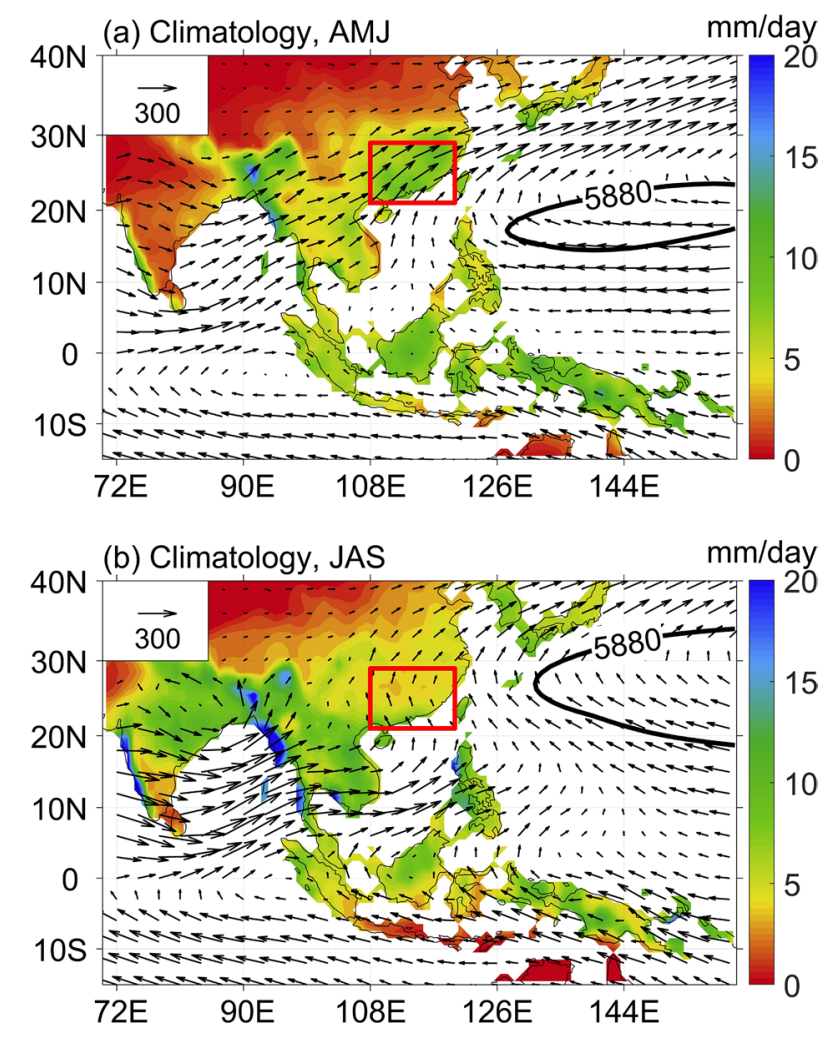

Fig. 11 Climatology of land rainfall (shading) and moisture flux (vectors; $\mathrm{kg} \mathrm{m}^{-1} \mathrm{~s}^{-1}$ ) over the Indian Ocean and western Pacific in a AMJ and $\mathbf{b}$ JAS. The black solid line in bold refers the $5880 \mathrm{gpm}$ contour line at $500 \mathrm{hPa}$ which can represent the WPSH

the first and second rainy seasons is likely attributable to their different climatological states (Fig. 11). We can see that SC is on the northwest of the WPSH (5880 gpm contour line) and receives the most precipitation among the East China monsoon region, meaning that the rainbelt is located in SC in AMJ. In this period, the SC rainfall will increase with a stronger WPSH, which means much moisture transported to SC from the SCS (Fig. 12a). Then the rainbelt shifts northward to the middle-lower reaches of the Yangtze River with the northward migration of the WPSH in JAS. Notably, the monsoon over SC is mainly southwesterly in AMJ and southerly in JAS. The southerly monsoon in JAS moves through SC area with very little blockages, meaning that plenty of moisture moves through SC but does not converge there; the moisture finally converges in the middlelower reaches of the Yangtze River. This indicates that the SC rainfall will not change substantially regardless of how the SCS meridional moisture flux changes. Thus, blocking the northward moisture flux transported out of SC, which means that the weakening and eastward retreat of the WPSH lead to a low-pressure center and a convergence of moisture in SC, seems to be an effective way to contribute to the anomalous SC rainfall in the second rainy season (Fig. 12b). 
(a) Anomalous hgt in $500 \mathrm{hPa} \&$ moisture flux, AMJ

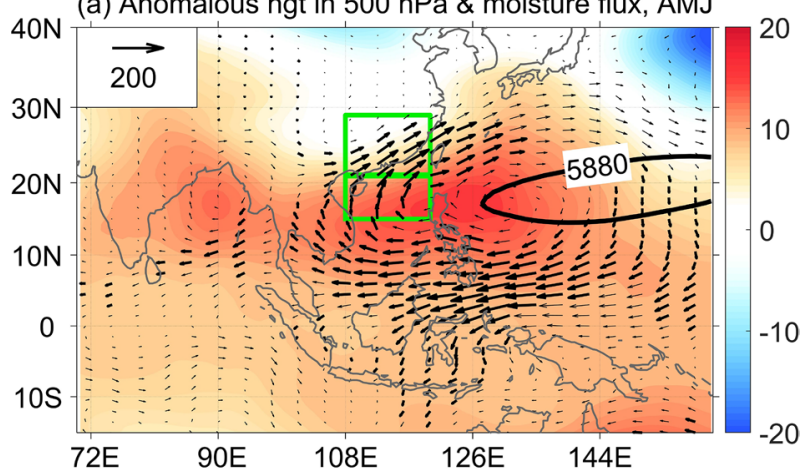

(b) Anomalous hgt in $500 \mathrm{hPa} \&$ moisture flux, JAS

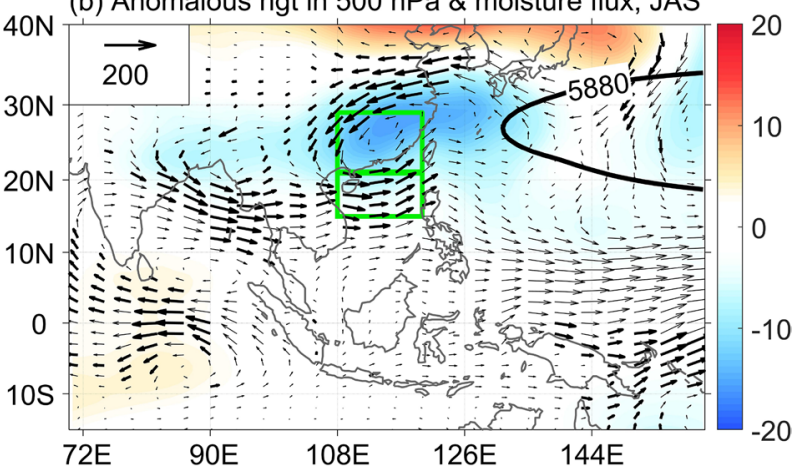

Fig. 12 Composite $500 \mathrm{hPa}$ geopotential height (shading; gpm) and moisture flux (vectors; $\mathrm{kg} \mathrm{m}^{-1} \mathrm{~s}^{-1}$ ) anomalies of positive SC rainfall cases minus those of the negative SC rainfall cases (beyond one standard deviation) in a AMJ and b JAS. The black solid line in bold refers the climatological $5880 \mathrm{gpm}$ contour line at $500 \mathrm{hPa}$. The two green boxes from north to south refer sequentially to SC and the SCS

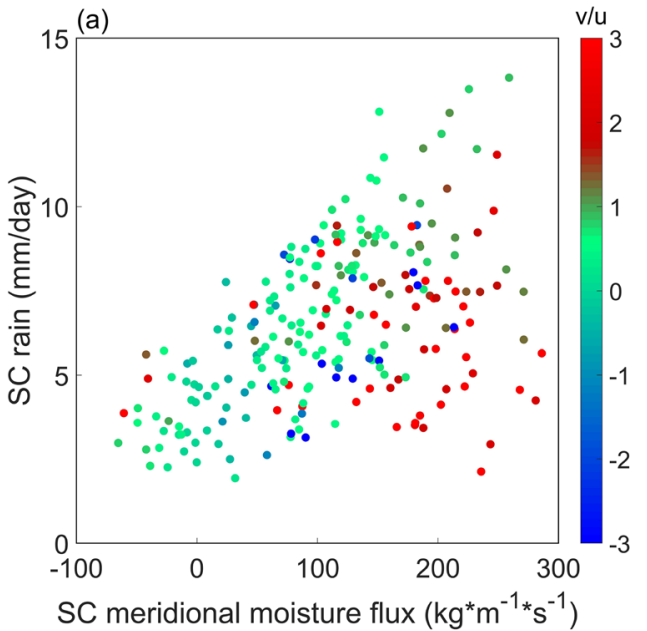

Fig. 13 Scatterplots of the SC rain index and SC meridional moisture flux. Each point corresponds to a month of the year. We define $\mathrm{u}$ as the zonal moisture flux and $\mathrm{v}$ as the meridional moisture flux. Shading in a refers to the ratio of meridional moisture flux to zonal moisture flux. Data in b are divided into strong (blue) and weak (red)
Additionally, scatterplots of the SC rainfall index and $\mathrm{SC}$ meridional moisture flux are shown in Fig. 13 to further explore the influence of the climatological state on the relationship between rainfall and moisture circulation. Generally, similar to the SCS meridional moisture flux, the meridional moisture flux in SC shows a positive correlation with the $\mathrm{SC}$ rainfall. However, the relationship becomes complex when the meridional moisture flux increases. As seen in Fig. 13, when the meridional moisture flux is strong (such as a threshold larger than $170 \mathrm{~kg} \mathrm{~m}^{-1} \mathrm{~s}^{-1}$ ) and the zonal moisture flux is weaker than the meridional component (red and blue points), there seems to be a negative trend. Therefore, we divide the points into two types (Fig. 13b): the red points represent the cases in which the SC meridional moisture flux is larger than $170 \mathrm{~kg} \mathrm{~m}^{-1} s^{-1}$ and larger than twice the absolute zonal moisture flux, and the blue points represent other cases. Obviously, when the meridional moisture flux is strong enough and the zonal moisture is weak, the SC rainfall will no longer increase along with the meridional moisture flux. In these situations, the meridional moisture flux more easily passes through SC and converges beyond the area north of SC. The climatology of the moisture circulations in Fig. 11 also supports this hypothesis well, as the amplitude of meridional and zonal moisture fluxes over SC is similar in AMJ, but the meridional moisture flux dominates in JAS.

Figure 14a shows the rainbelt shift in the East China monsoon region along the latitudinal direction. From the changes of precipitation departure percentage, we can easily find the rainbelt shift in summer. The rainbelt reaches its northernmost position in July and August, which is beyond the area north of SC. The correlation between the rainfall in the East

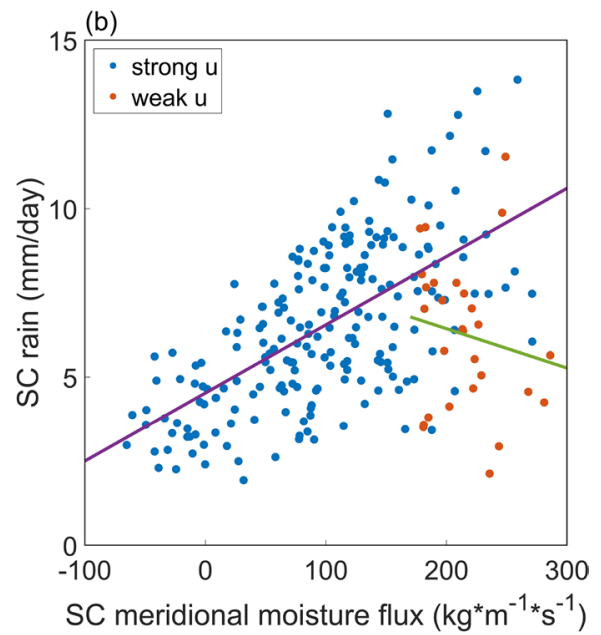

zonal moisture fluxes, with the criterion that the zonal moisture flux is larger (or not) than half of the meridional moisture flux. In addition, the meridional moisture flux of the red dots must be larger than $170 \mathrm{~kg} \mathrm{~m}^{-1} s^{-1}$ ) 

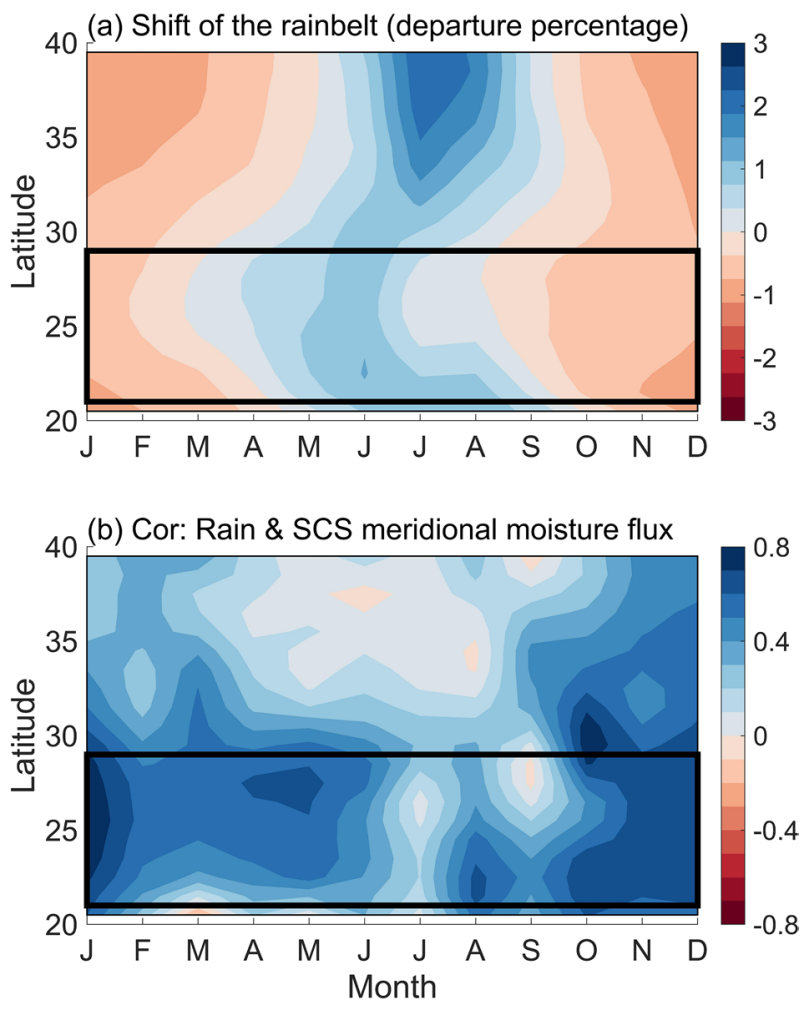

Fig. 14 a Seasonal cycle of the precipitation departure percentages (the ratio of the monthly anomalies divided by the annual average) in the East China monsoon region $\left(108^{\circ} \mathrm{E}-120^{\circ} \mathrm{E}\right)$ along the latitudinal direction and $\mathbf{b}$ the correlation between rainfall in the East China monsoon region and SCS meridional moisture flux. The black boxes refer to the region between $21^{\circ} \mathrm{N}$ and $29^{\circ} \mathrm{N}$, namely, the latitudes of $\mathrm{SC}$

China monsoon region and the SCS meridional moisture flux is shown in Fig. 14b. The correlation in AMJ is large and shows a uniform distribution in SC. Nevertheless, in the second rainy season, the correlation is not large, and the northern and southern parts of SC exhibit different relationships with the SCS meridional moisture flux. In July, when the rainbelt is beyond the area north of SC and reaches its northernmost position, the correlation also reaches its lowest level. Note that the northern part of SC $\left(25^{\circ} \mathrm{N}-29^{\circ} \mathrm{N}\right)$ is a lower precipitation zone in JAS (Fig. 14a), which means that the moisture does not converge there. Thus, the corresponding correlation of the northern part rainfall of SC with the SCS meridional moisture flux is small in JAS (Fig. 14b).

\subsection{Differences between July, August and September in the second rainy season}

In addition to the differences between the first and second rainy seasons, we also notice that distinct differences exist among three months of the second rainy season. As shown in Fig. 2b, the correlation between the SC rainfall and SCS
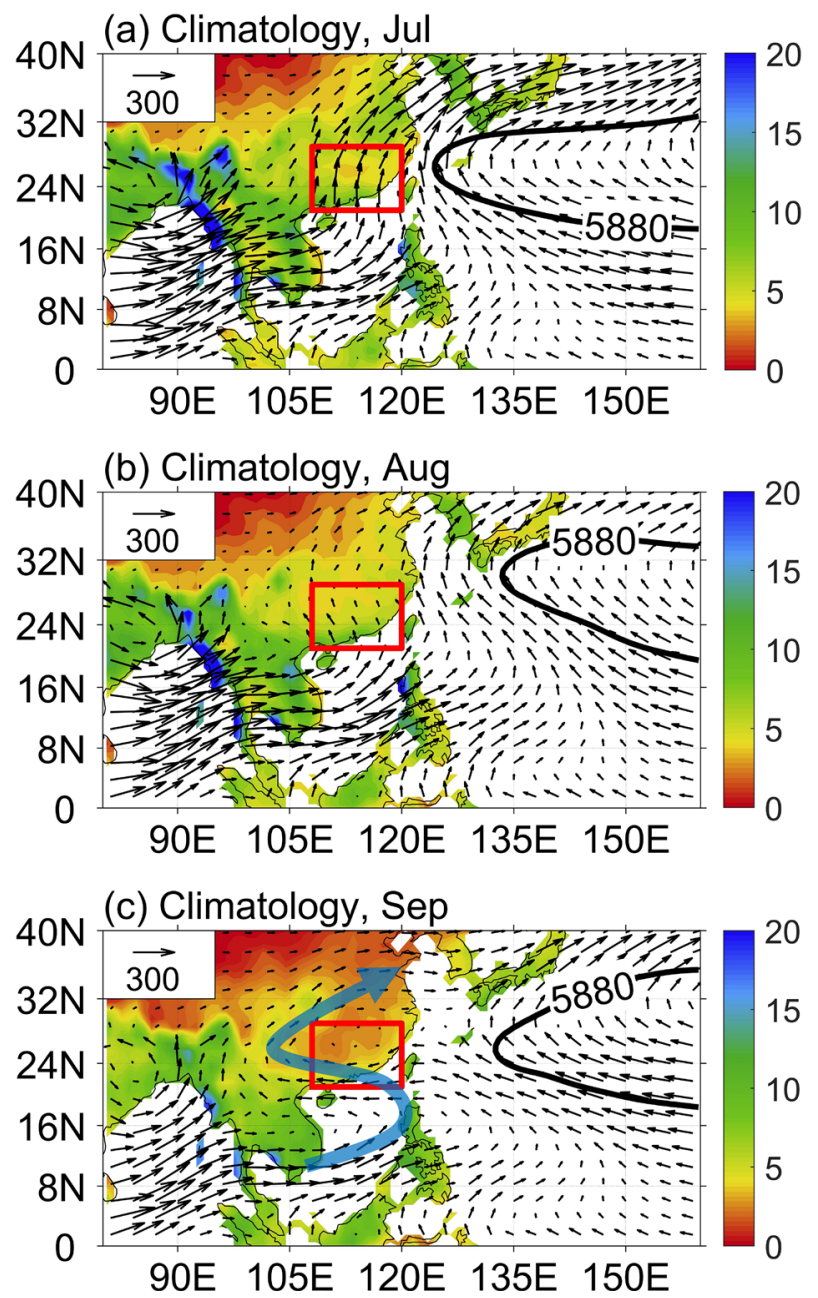

Fig. 15 Climatology of land rainfall (shading; mm/day) and moisture flux (vectors; $\mathrm{kg} \mathrm{m}^{-1} \mathrm{~s}^{-1}$ ) over the Indian Ocean and Western Pacific in a July, b August and c September. The black solid line in bold refers the $5880 \mathrm{gpm}$ contour line at $500 \mathrm{hPa}$

meridional moisture flux in July is much lower than those in August and September, while the correlation in August is larger and not far from that in the first rainy season.

Figure 15 shows the climatology of land rainfall (shading) and moisture flux (vectors) over the Indian Ocean and western Pacific in July, August and September. The moisture circulation in July is most similar to that in Fig. 11b; the meridional moisture flux is strong in the SC region. This means that the SCS meridional moisture easily passes through SC and converges in the middle and lower reaches of the Yangtze River, with little moisture remaining in SC. The distribution of rainfall corresponding to this action is an obvious rainfall belt north of SC. In August, the WPSH continues to move north, and SC is on the southwest of the WPSH. The rainbelt also moves to Northern China, but the correlation between the rainfall of the Northern China and the SCS meridional moisture flux is low in August 
(Fig. 14b). That means that the SCS moisture flux cannot reach Northern China in August (Fig. 15b). It is interesting that the moisture circulation in September near SC presents a trajectory similar to the letter "s". This is because the zonal pressure (height) gradient on the west side of the WPSH is very small in September (Fig. S4c). In September, the 5880 gpm contour line is in the east, but the 5870 gpm contour line extends westward, which means the zonal height (pressure) gradient is small and leads to weak meridional moisture flux. Actually, the north part of the "s" trajectory of moisture flux matches well with the $5870 \mathrm{gpm}$ contour line in September (Fig. S4c). The SCS moisture flux shows a cyclonic pattern and then moves westward to the south of $\mathrm{SC}$ and is finally transported northwestward. This circulation trajectory explains the poor correlation of the SCS meridional moisture flux with rainfall north of $\mathrm{SC}\left(25^{\circ} \mathrm{N}-29^{\circ} \mathrm{N}\right)$ in Fig. 14b.

The "blocking" hypothesis is also supported by the vertical distribution of the composite meridional moisture flux anomalies (Fig. 16). When both the meridional and zonal components of moisture flux exist, the positive anomalous $\mathrm{SC}$ rainfall corresponds to a convergence of moisture flux in $\mathrm{SC}$ and the southern part of the convergence pattern (the SCS part) is dominant. However, the SC region is not at the convergence center but lies on the northern part of the convergence pattern in July. The north part is significant, and its amplitude is stronger than the southern part. This means that the anomalous SC rainfall in July occurs because of the blocking of moisture flux out of SC across the northern boundary, while the rainfall occurs in the other months mainly because of the moisture flux strengthening across the southern boundary of SC.

Similar to Fig. 9, Fig. 17 presents the composites of the moisture transport anomalies across each boundary of SC for positive and negative cases of the SC rainfall in July, August and September. As mentioned above, positive SC rainfall in July was mainly caused by the southward moisture flux anomaly across the northern boundary of SC, that is, by northward moisture circulation blocking out of SC. However, the northern boundary is not as important in August. There exists an asymmetry in the SC rainfall in August. Moisture flux transported into SC across the southern boundary takes a dominant position in the anomalous positive $\mathrm{SC}$ rainfall occurrences, whereas both of the moisture fluxes transported out of SC across the southern and northern boundaries make half of the contribution to the anomalous negative SC rainfall events. In September, the contribution of each boundary is more scattered and the western boundary can take a half, which implies the zonal moisture transport may plays a more important role in this period.

Figure 18 shows the composite rainfall and moisture flux anomalies of extreme SC rainfall cases from June to September and presents a schematic anomalous circulation for each month. The circulation with an anomalous anticyclone over the WNP-SCS in June can represent the situation in the first rainy season, which strengthens the SCS meridional moisture flux and leads to more moisture convergence over SC. The anomalous circulation in July is accompanied by an anomalous cyclone over SC and the East China Sea. Located southwest of the anomalous cyclone, there is almost
Fig. 16 Distribution of the composite meridional moisture flux anomalies of positive SC rainfall cases in a June, b July, c August and d September. The longitude is from $108^{\circ} \mathrm{E}$ to $120^{\circ} \mathrm{E}$ and the green lines indicate the $\mathrm{SC}$ region. Areas with $95 \%$ or more confidence are shaded with dots
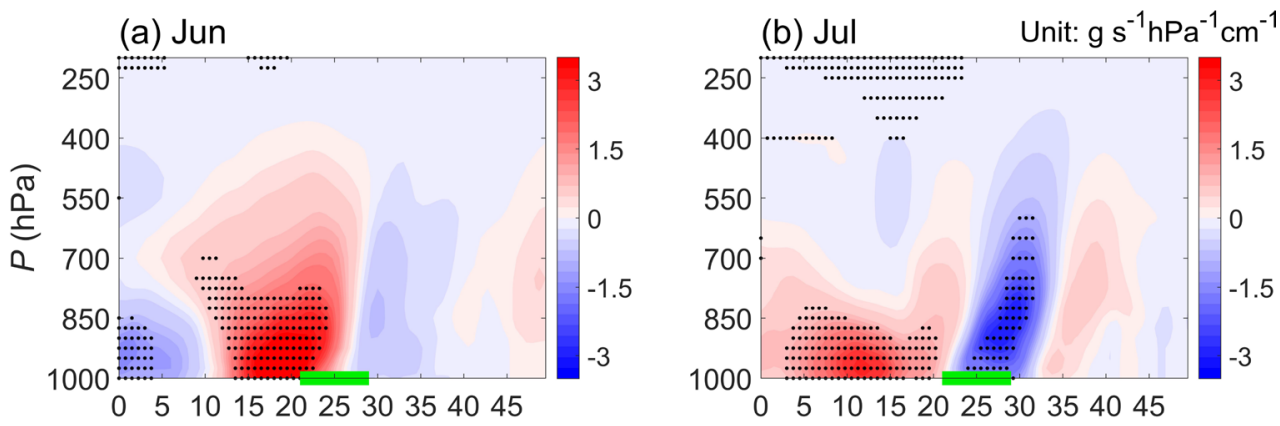

(c) Aug

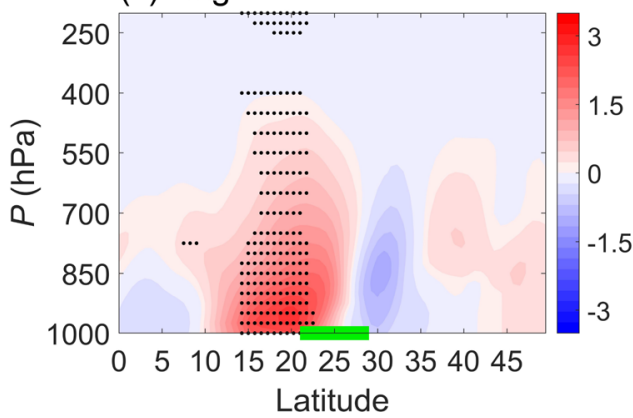

(d) Sep

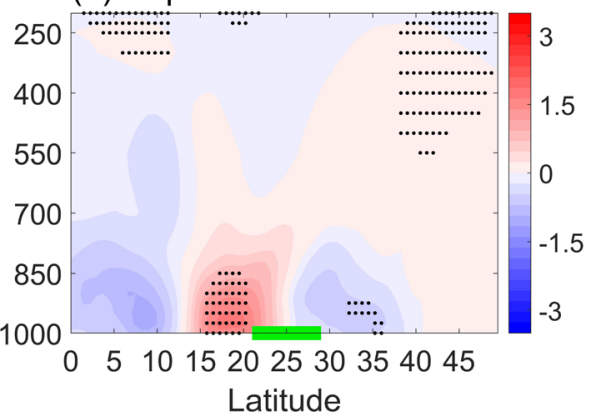


Fig. 17 Composites of the moisture transport anomalies (Sv) across each boundary of $\mathrm{SC}$ as well as the total moisture transport anomalies converged over the SC area for the positive and negative phases of SC rainfall (beyond one standard deviation) in a July, b August and $\mathbf{c}$ September. The percentages above the bars indicate the contributions of each boundary to the whole moisture flux anomalies transported into (positive cases) or out of (negative cases) SC

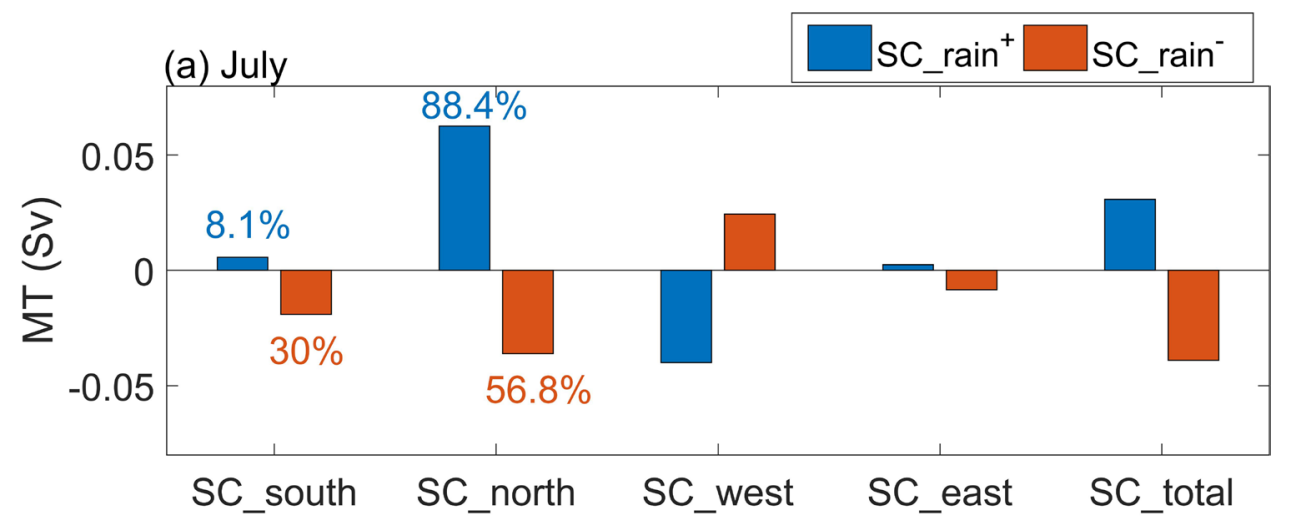

(b) August

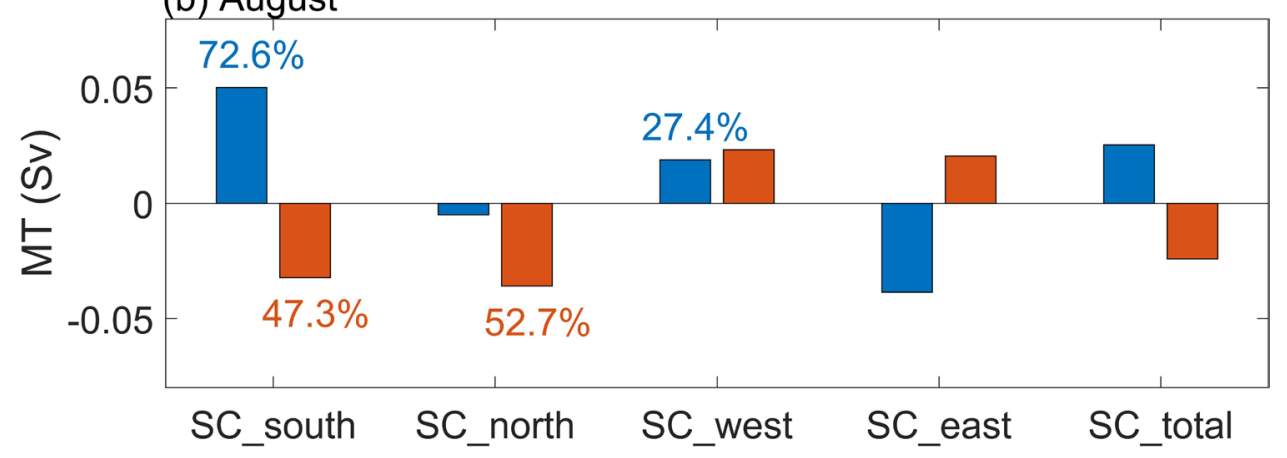

(c) September

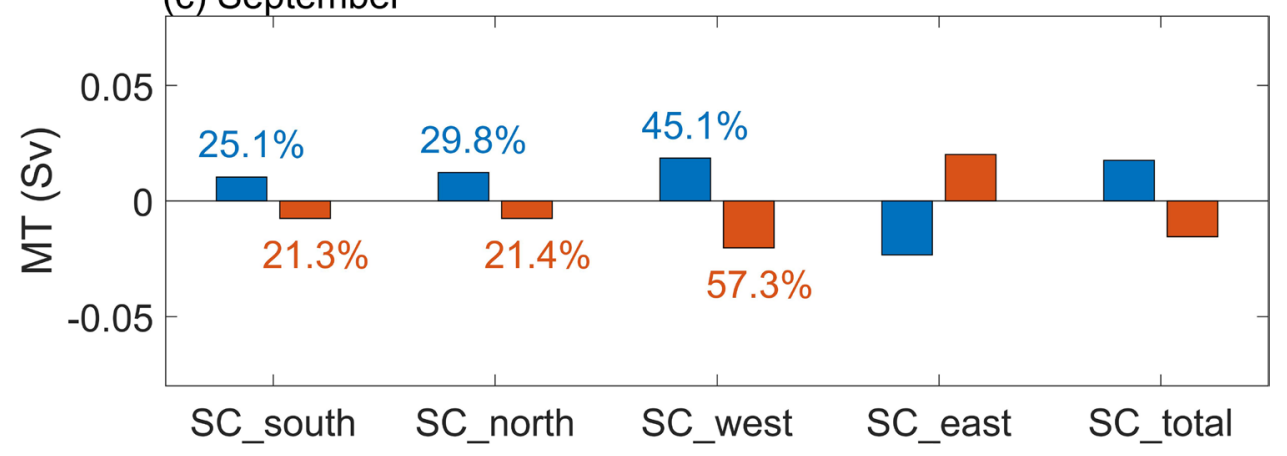

no anomalous meridional moisture flux transported into SC. In August, an anomalous anticyclone and an anomalous cyclone exist at the same time. Because the SCS is located northwest of the anomalous anticyclone and south of the anomalous cyclone, both anomalous circulation patterns contribute to the SCS meridional moisture flux transported into SC. In September, an anomalous cyclone exists over the $\mathrm{SC}$ region but is much smaller than that in July. Therefore, the SCS meridional moisture flux can still be transported into SC, while the northerly anomalous moisture flux across the northern boundary also exists. Together, they contribute to the convergence of moisture over SC, which is consistent with Fig. 16d. In conclusion, July, August and September share a common characteristic that the anomalous cyclone over the SC region affects the SC rainfall changes in the second rainy season. However, the latitude of the WPSH ridge and the longitude of its westernmost point lead to the different positions of the anomalous cyclone, and further result in internal differences in the second rainy season.

\section{Conclusions and summary}

A high positive correlation between the SCS meridional moisture flux and the SC rainfall is observed in the first rainy season (AMJ). A decomposition analysis shows that the SCS meridional moisture flux anomaly associated with the anomalous SC rainfall is mainly determined by wind component. The wind variations are then modulated by the position and intensity of the WPSH. A composite analysis indicates that 

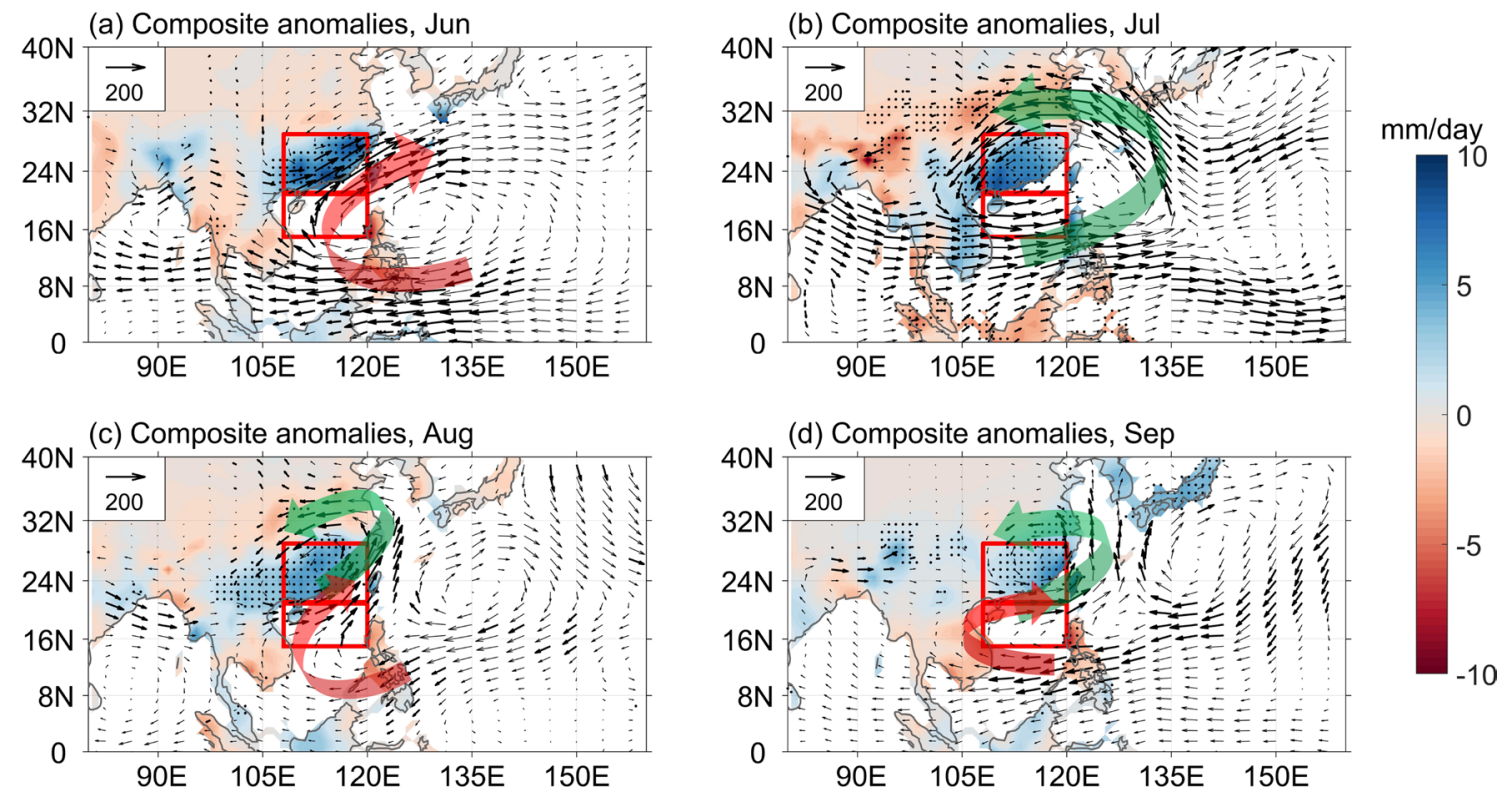

Fig. 18 Composite rainfall (shading; $\mathrm{mm} /$ day) and moisture flux (vectors; $\mathrm{kg} \mathrm{m}^{-1} \mathrm{~s}^{-1}$ ) anomalies of positive $\mathrm{SC}$ rainfall cases minus those of the negative SC rainfall cases in a June, b July, $\mathbf{c}$ August and d September. Rainfall with $95 \%$ or more confidence is shaded with

dots, and moisture fluxes greater than $95 \%$ confidence are in bold. The large arrows show the schematic of the anomalous circulation. Schematically, red arrows refer to anomalous anticyclones over WNP$\mathrm{SCS}$, and green arrows refer to anomalous cyclones over SC

the anomalous SC rainfall cases and anomalous SCS meridional moisture flux cases in AMJ share common moisture circulations and rainfall distributions. When the SC rainfall or SCS meridional moisture flux is positive, there will be an anomalous anticyclone over the WNP-SCS region (Wang and Zhang 2002; Xie et al. 2016; Xu et al. 2019) with the enhancement and westward extension of the WPSH. Located southwest of the anomalous anticyclone, the SCS will transport more moisture northward into SC across the southern boundary of SC, which leads to an anomalous convergence of moisture flux over SC and results in more precipitation.

Considering that the anomalous anticyclone over the WNP-SCS is generally regarded as a signal of ENSO (Zhang et al. 1996; Weisberg and Wang 1997; Wang et al. 1999, 2009; Wang et al. 2000), we compute partial correlations between the SCS, TNWP, Nino 3 index and moisture flux over East Asia. Although the intensity of the SC rainfall is modulated by ENSO or the TNWP through influencing the moisture flux of the SCS, the relationship of the SCS meridional moisture flux with the SC rainfall is robust and nearly unaffected by ENSO and the TNWP. That is, the SCS is not only the intermediary in which the TNWP and ENSO affect the SC rainfall but also plays an independent role in the modulation of the $\mathrm{SC}$ rainfall.

However, a large proportion of moisture flux from the SCS does not converge in SC in the second rainy season (JAS). As a result, the SC rainfall will not completely increase with the SCS meridional moisture flux, and thus the correlation of the SCS meridional moisture flux with the

SC rainfall is not high in the second rainy season. Instead, there is an anomalous cyclonic circulation over SC that is accompanied by positive $\mathrm{SC}$ rainfall cases, suppressing the moisture flux out of SC across its northern boundary in the second rainy season. This anomalous cyclone is related to the weakening and eastward retreat of the WPSH in JAS when it is north of SC. Briefly, strengthening the meridional moisture flux into SC across its southern boundary is important, or suppressing the moisture flux out of SC across its northern boundary is important, depending on whether or not the moisture from the SCS can converge in SC. It depends on the relative position of SC and the WPSH, and dominated by the amplitude of meridional moisture flux and the relative sizes of the meridional and zonal moisture fluxes in SC. Generally, the moisture flux transported into SC across the southern boundary dominates the SC rainfall because the SCS meridional moisture flux is mainly determined by the wind change. This means that the southerly summer monsoon across the southern boundary dominates the SC rainfall, rather than the northern or zonal boundaries.

However, for the second rainy season especially July, when the WPSH is on the east of SC, the meridional moisture flux is strong enough and the zonal moisture flux is weak in SC. Thus, the meridional moisture flux easily passes through SC to the middle and lower reaches of the Yangtze River, without the process of convergence and precipitation in SC. In this regime, strengthening the meridional moisture flux into SC has little effect on the rainfall. As a result, blocking the northward moisture flux transported out of SC, 
which leads to a convergence of moisture in SC, seems to be an effective way to contribute to the positive SC rainfall. However, September is another story. Because of the special pressure field and "s-shaped" pattern of moisture circulation, moisture flux coming from the SCS cannot influence the northern part of SC, and the moisture flux out of the SC region across its western boundary becomes a significant factor in the SC rainfall.

Both the anomalous anticyclone over WNP-SCS and cyclone over SC can exist at the same time, such as the anomalous moisture circulation in August with extreme SC rainfall events. Overall, the position and scale of the anomalous cyclone, the presence or absence of the anomalous anticyclone and the climatological state of moisture circulation can all influence the relationship between the SCS moisture flux and the SC rainfall. It seems not to be just controlled by the changes of the WPSH. Thus, more detailed work and model validation can be done to further explore the influence of these factors on the relationship between the SC rainfall and adjacent moisture circulation, such as the asymmetry that occurs in August.

Acknowledgments This paper is part of X. Li's $\mathrm{PhD}$ thesis which is performed in the State Key Laboratory of Tropical Oceanography, South China Sea Institute of Oceanology, Chinese Academy of Sciences. The study is supported by the Strategic Priority Research Program of the Chinese Academy of Sciences (XDA20060502 and XDB42000000), the National Key Research and Development Program of China (2019YFA0606701), the National Natural Science Foundation of China (41731173), Key Special Project for Introduced Talents Team of Southern Marine Science and Engineering Guangdong Laboratory (Guangzhou) (GML2019ZD0306), Innovation Academy of South China Sea Ecology and Environmental Engineering, Chinese Academy of Sciences (ISEE2018PY06), and the Leading Talents of Guangdong Province Program.

Open Access This article is licensed under a Creative Commons Attribution 4.0 International License, which permits use, sharing, adaptation, distribution and reproduction in any medium or format, as long as you give appropriate credit to the original author(s) and the source, provide a link to the Creative Commons licence, and indicate if changes were made. The images or other third party material in this article are included in the article's Creative Commons licence, unless indicated otherwise in a credit line to the material. If material is not included in the article's Creative Commons licence and your intended use is not permitted by statutory regulation or exceeds the permitted use, you will need to obtain permission directly from the copyright holder. To view a copy of this licence, visit http://creativecommons.org/licenses/by/4.0/.

\section{References}

Adler RF, Sapiano MRP, Huffman GJ et al (2018) The Global Precipitation Climatology Project (GPCP) monthly analysis (New Version 2.3) and a review of 2017 global precipitation. Atmosphere (Basel). https://doi.org/10.3390/atmos9040138

Berrisford P, Dee D, Fielding K et al (2009) ERA report series - the ERA-Interim archive Version 1.0. Weather 16
Chen SX, Gao SF, Yang S (1983) The source of water vapor in the southern part of China in May and June and its abnormality. Proceedings of the symposium on the summer monsoon in South East Asia (in Chinese). People's Press of Yunnan Province 97-110

Chen M, Xie P, Janowiak JE (2002) Global land precipitation: a 50-yr monthly analysis based on gauge observations. J Hydrometeorol 3:249-266. https://doi.org/10.1175/1525-7541(2002)003\%3c024 9:GLPAYM\%3e2.0.CO;2

Chen CS, Lin KP, Wang PX (2004) Relation between pre-flood season precipitation anomalies in South China and water Vapor Transportation (in Chinese). J Nanjing Inst Meteorol 27(6):721-727

Dee DP, Uppala SM, Simmons AJ et al (2011) The ERA-Interim reanalysis: configuration and performance of the data assimilation system. Q J R Meteorol Soc 137:553-597. https://doi.org/10.1002/ qj. 828

Ding YH (1992) Summer monsoon rainfalls in China. J Meteorol Soc Jpn 70:373-396

Ding YH, Wang ZY (2008) A study of rainy seasons in China. Meteorol Atmos Phys 100:121-138. https://doi.org/10.1007/s0070 3-008-0299-2

Fang Y, Chen W, Zhou W (2012) Analysis of the role played by circulation in the persistent precipitation over South China in June 2010. Adv Atmos Sci 29:769-781. https://doi.org/10.1007/s0037 6-012-2018-7

Feng J, Chen W, Tam CY, Zhou W (2011) Different impacts of El Niño and El Niño Modoki on China rainfall in the decaying phases. Int J Climatol 31:2091-2101. https://doi.org/10.1002/joc.2217

Gao L, Huang J, Chen X et al (2017) Risk of extreme precipitation under nonstationarity conditions during the second flood season in the Southeastern Coastal Region of China. J Hydrometeorol 18:669-681. https://doi.org/10.1175/JHM-D-16-0119.1

$\mathrm{Gu}$ W, Wang L, Hu ZZ et al (2018) Interannual variations of the first rainy season precipitation over South China. J Clim 31:623-640. https://doi.org/10.1175/JCLI-D-17-0284.1

Herdies DL, Da Silva A, Silva Dias MAF, Ferreira RN (2002) Moisture budget of the bimodal pattern of the summer circulation over South America. J Geophys Res Atmos 107:LBA 42-1-LBA 42-10. doi: https://doi.org/10.1029/2001JD000997

Huang RH, Zhang ZZ, Huang G (1998) Characteristics of the water vapor transport in East Asian monsoon region and its difference from that in South Asian monsoon region in summer (in Chinese). Sci Atmos Sin 22:460-469

Jiang F, Zhang W, Geng X et al (2019) Impacts of Central Pacific El Niño on Southern China spring precipitation controlled by its longitudinal position. J Clim. https://doi.org/10.1175/ JCLI-D-19-0266.1

Leung MY-T, Zhou W, Wang D et al (2020) Remote tropical western Indian Ocean forcing on changes in June precipitation in South China and the Indochina peninsula. J Clim. https://doi. org/10.1175/jcli-d-19-0626.1

Li WP (1999) Moisture flux and water balance over the South China Sea during Late Boreal spring and summer. Theor Appl Climatol 64:179-187. https://doi.org/10.1007/s007040050121

Li X, Zhou W, Li C, Song J (2013) Comparison of the annual cycles of moisture supply over Southwest and Southeast China. J Clim 26:10139-10158. https://doi.org/10.1175/JCLI-D-13-00057.1

Lin L, Feng Y, Huang Z et al (2006) Technical manual for weather forecast in Guangdong Province. China Meteorological Press, Beijing

Ma W, Huang W, Yang Z et al (2018) Dynamic and thermodynamic factors associated with different precipitation regimes over south China during pre-monsoon season. Atmosphere (Basel). https:// doi.org/10.3390/atmos9060219

Matsumoto J (1997) Seasonal transition of summer rainy season over Indochina and adjacent monsoon region. Adv Atmos Sci 14:231245. https://doi.org/10.1007/s00376-997-0022-0 
Saji NH, Yamagata T (2003) Possible impacts of Indian Ocean Dipole mode events on global climate. Clim Res 25:151-169. https://doi. org/10.3354/cr025151

Sun B, Wang H, Zhou B (2019) Interdecadal Variation of the Relationship between East Asian Water Vapor Transport and Tropical Pacific Sea Surface Temperatures during January and Associated Mechanisms. J Clim. https://doi.org/10.1175/jcli-d-19-0290.1

Tanaka M (1992) Intraseasonal oscillation and the onset and retreat dates of the summer monsoon over east, Southeast Asia and the Western Pacific region using GMS high cloud amount data. J Meteorol Soc Japan. https://doi.org/10.2151/jmsj1965.70.1B_613

Tao L, Li T, Ke YH, Zhao JW (2017) Causes of interannual and interdecadal variations of the summertime Pacific-Japan-like pattern over East Asia. J Clim 30:8845-8864. https://doi.org/10.1175/ JCLI-D-15-0817.1

Trenberth KE (1991) Climate diagnostics from global analyses: conservation of mass in ECMWF analyses. J Clim 4:707-722. https:// doi.org/10.1175/1520-0442(1991)004<0707:CDFGAC > 2.0.CO;2

Wang C, Wang X (2013) Classifying el niño modoki I and II by different impacts on rainfall in southern China and typhoon tracks. J Clim 26:1322-1338. https://doi.org/10.1175/JCLI-D-12-00107.1

Wang C, Weisberg RH, Virmani JI (1999) Western Pacific interannual variability associated with the El Niño-Southern Oscillation. J Geophys Res Ocean 104:5131-5149. https://doi. org/10.1029/1998JC900090

Wang B, Zhang Q (2002) Pacific-East Asian teleconnection. Part II: How the Philippine Sea anomalous anticyclone is established during El Niño development. J Clim 15:3252-3265. https://doi. org/10.1175/1520-0442(2002)015\%3c3252:PEATPI\%3e2.0.CO;2

Wang B, Wu R, Fu X (2000) Pacific-East Asian teleconnection: how does ENSO affect East Asian climate? J Clim 13:1517-1536. https://doi.org/10.1175/1520-0442(2000)013\%3c1517:PEATH $\mathrm{D} \% 3 \mathrm{e} 2.0 . \mathrm{CO} ; 2$

Wang B, Huang F, Wu Z et al (2009) Multi-scale climate variability of the South China Sea monsoon: a review. Dyn Atmos Ocean 47:15-37. https://doi.org/10.1016/j.dynatmoce.2008.09.004

Wang C, Zhang L, Lee S-K (2013) Response of freshwater flux and sea surface salinity to variability of the Atlantic warm pool. J Clim 26:1249-1267. https://doi.org/10.1175/jcli-d-12-00284.1

Wang Q, Cai W, Zeng L, Wang D (2018) Nonlinear meridional moisture advection and the ENSO-Southern China rainfall teleconnection. Geophys Res Lett 45:4353-4360. https://doi. org/10.1029/2018GL077446

Wang Q, Cai W, Zhong W et al (2019) Response of southern China winter rainfall to El Niño diversity and its relevance to projected southern China rainfall change. J Clim 32:3343-3356. https://doi. org/10.1175/JCLI-D-18-0571.1

Watanabe M, Jin F (2002) Role of Indian Ocean warming in the development of Philippine Sea anticyclone during ENSO. Geophys Res Lett 29:116-1-116-4. doi: https://doi.org/10.1029/2001g1014318
Wu L, Shao Y, Cheng AYS (2011) A diagnostic study of two heavy rainfall events in South China. Meteorol Atmos Phys 111:13-25. https://doi.org/10.1007/s00703-010-0112-x

Xiao F, Wang D, Leung MYT (2020) Early and extreme warming in the South China Sea during 2015/2016: role of an unusual Indian Ocean Dipole Event. Geophys Res Lett. https://doi. org/10.1029/2020GL089936

Xie M, Wang C (2020) Decadal Variability of the Anticyclone in the Western North Pacific. J Clim 33:9031-9043. https://doi. org/10.1175/JCLI-D-20-0008.1

Xie SP, Kosaka Y, Du Y et al (2016) Indo-western Pacific ocean capacitor and coherent climate anomalies in post-ENSO summer: a review. Adv Atmos Sci 33:411-432. https://doi.org/10.1007/ s00376-015-5192-6

Xu K, Huang QL, Tam CY et al (2019) Roles of tropical SST patterns during two types of ENSO in modulating wintertime rainfall over southern China. Clim Dyn 52:523-538. https://doi.org/10.1007/ s00382-018-4170-y

Yuan Y, Yang S (2012) Impacts of different types of El NiñO on the East Asian climate: Focus on ENSO cycles. J Clim 25:7702-7722. https://doi.org/10.1175/JCLI-D-11-00576.1

Yuan C, Liu J, Luo JJ, Guan Z (2019) Influences of tropical Indian and Pacific Oceans on the interannual variations of precipitation in the early and late rainy seasons in South China. J Clim 32:3681-3694. https://doi.org/10.1175/JCLI-D-18-0588.1

Zeng L, Schmitt RW, Li L et al (2019) Forecast of summer precipitation in the Yangtze River Valley based on South China Sea springtime sea surface salinity. Clim Dyn 53:5495-5509. https://doi. org/10.1007/s00382-019-04878-y

Zhang R, Sumi A (2002) Moisture circulation over East Asia during El Niño episode in northern winter, spring and autumn. J Meteorol Soc Jpn 80:213-227. https://doi.org/10.2151/jmsj.80.213

Zhang R, Sumi A, Kimoto M (1996) Impact of El Niño on the East Asian Monsoon: a diagnostic study of the ' $86 / 87$ and ' $91 / 92$ events. J Meteorol Soc Jpn 1:996. https://doi.org/10.2151/jmsj1 965.74.1_49

Zhang R, Sumi A, Kimoto M (1999) A diagnostic study of the impact of El Niño on the precipitation in China. Adv Atmos Sci 16:229 241. https://doi.org/10.1007/BF02973084

Zhou TJ, Yu RC (2005) Atmospheric water vapor transport associated with typical anomalous summer rainfall patterns in China. J Geophys Res D Atmos 110:1-10. https://doi.org/10.1029/2004J D005413

Publisher's Note Springer Nature remains neutral with regard to jurisdictional claims in published maps and institutional affiliations. 